\title{
In Vivo Structural Neuroanatomy of Corpus Callosum in Alzheimer's Disease and Mild Cognitive Impairment Using Different MRI Techniques: A Review
}

\author{
Margherita Di Paola ${ }^{\mathrm{a}, \mathrm{b}, *}$, Gianfranco Spalletta ${ }^{\mathrm{a}}$ and Carlo Caltagirone ${ }^{\mathrm{a}, \mathrm{c}}$ \\ ${ }^{a}$ Clinical and Behavioural Neurology, IRCCS Santa Lucia Foundation, Rome, Italy \\ ${ }^{\mathrm{b}}$ Department of Internal Medicine and Public Health, University of L'A quila, Italy \\ ${ }^{c}$ Department of Neurological Neuroscience, University of Rome "Tor Vergata", Italy
}

Handling Associate Editor: Cindy Carlsson

Accepted 27 November 2009

\begin{abstract}
The corpus callosum (CC), which connects the two cerebral hemispheres, is the largest white matter fiber bundle in the human brain. This structure presents a peculiar myelination pattern: it has small diameter fibers, located in the genu, which myelinate much later in normal development, and large diameter fibers of the splenium, which myelinate early in development. Although the pathology of AD mainly involves the cerebral gray matter structure, there is evidence that white matter may also be involved. To illustrate callosal white matter changes in AD pathology, in this review we summarize in vivo imaging studies in humans, focusing on region of interest, voxel-based morphometry, diffusion-weighted imaging, and diffusion tensor imaging techniques. Our aims were to identify where in the $\mathrm{CC}$, when in the different stages of $\mathrm{AD}$, and how callosal changes can be detected with different MRI techniques. Results showed that changes in the anterior (genu and anterior body) as well as in the posterior (isthmus and splenum) portions of the $\mathrm{CC}$ might already be present in the early stages of AD. These findings support the hypothesis that two mechanisms, Wallerian degeneration and myelin breakdown, might be responsible for the region-specific changes detected in $\mathrm{AD}$ patients. Wallerian degeneration affects the posterior $\mathrm{CC}$ subregion, which receives axons directly from those brain areas (temporo-parietal lobe regions) primarily affected by the AD pathology. Instead, the myelin breakdown process affects the later-myelinating CC subregion and explains the earlier involvement of the genu in CC atrophy.
\end{abstract}

Keywords: Alzheimer's disease, corpus callosum, diffuse tensor imaging, diffusion-weighted imaging, mild cognitive impairment, region of interest, voxel-based morphometry

\section{INTRODUCTION}

Although research in the field of Alzheimer's disease (AD) has basically focused on gray matter (GM) de-

* Correspondence to: Dr. Margherita Di Paola, IRCCS Santa Lucia Foundation, Via Ardeatina 306, 00179 Rome, Italy. Tel.: +39 06 51501215; Fax: +39 06 51501213; E-mail: m.dipaola@hsantalucia. it. generation, a number of investigations have also documented a general white matter (WM) pathology associated with AD [1-6]. The corpus callosum (CC) has been implicated in this process [7-21]. In particular, it has been suggested that callosal atrophy in AD is the anatomical correlate of Wallerian degeneration of commissural nerve fibers. Thus, it might occur as a consequence of the death of projecting pyramidal cells in layer III of the neocortex and might reflect the pat- 
tern of neocortical neurodegeneration and the resulting cognitive dysfunction [13,22-26].

Unfortunately, in spite of the plethora of studies on callosal changes in $\mathrm{AD}$, results are unclear. Although it is commonly accepted that in AD patients, $\mathrm{CC}$ atrophy is mainly located in the anterior (genu and anterior body) and posterior (isthmus and splenium) subregions, it is less clear whether this finding is consistent in the different stages of AD pathology and across different methods.

In fact, the main result mentioned above, that is atrophy mainly in the callosal anterior and posterior subregions, comes from studies of AD groups that included patients in different illness stages, ranging from mild to severe dementia $[7,8,10-12,14-19,23-25,27-$ 43] and sometimes selected using different diagnostic criteria [10,14].

Furthermore, it has been found that different methods can produce different results. With regard to the region of interest (ROI) studies, for example, it has been shown that the earlier findings relied on manually tracing the $\mathrm{CC}$ and on the common callosal parcellation schemes (i.e., according to Witelson [19,44]; Weis [45-47]; or Hampel [11,18]) have generated a controversy regarding the assumed topography of callosal fibers [48]. In fact, in a previous study, we demonstrated that pre-defining callosal regions can give rise to misleading results [7]. This is also true for the voxelbased morphometry (VBM) technique. Senjem and colleagues [49] found that changes in the image processing chain of VBM noticeably influenced the results of inter-group morphometric comparisons. For example, the so-called "Optimized VBM" produced different results from those obtained with standard VBM.

Diffuse tensor imaging (DTI) studies have also produced different results. The vast majority of DTI studies are calculated as the diffusion parameters mean diffusivity (MD), which is a measure of the average motion of water molecules, independent of tissue directionality, and fractional anisotropy (FA), which measures the directionality of water diffusion. The pathological process of AD should alter both MD and FA values in the direction of lesser restriction on the movement of water and, therefore, with an increase in diffusivity (MD) and a decrease in anisotropy (FA). Nevertheless, in anatomically well-oriented structures, such as the $\mathrm{CC}$, these two parameters seem to remain in the normal range. Thus, many DTI studies conclude that in the $\mathrm{CC}$ there is no difference between $\mathrm{AD}$ patients and healthy controls (HC).

Two main open questions motivated the present review: i) how early callosal atrophy occurs in $\mathrm{AD}$ and whether the callosal changes involving the anterior and the posterior subregions can already be detected in mild $\mathrm{AD}$ and amnesic mild cognitive impairment (MCI); and ii) which magnetic resonance imaging (MRI) techniques are most useful for detecting callosal changes. Therefore, this review is focused on exploring how the $\mathrm{CC}$ changes in the different stages of $\mathrm{AD}$ and in MCI (i.e., in the preclinical stage of dementia and in the group at highest risk for developing dementia) [50-52], and which measurements have been applied to study these modifications in vivo.

\section{MATERIAL AND METHODS}

A detailed search of the literature was conducted. For our purposes, the database was selected using PubMed Services to research the following keywords: corpus callosum, white matter, Alzheimer's disease, mild cognitive impairment, region of interest, voxel-based morphometry, diffusion-weighted imaging, and diffusion tensor imaging. In examining research results, we paid attention to the clinical features of the patient groups to classify results obtained evaluating heterogeneous groups of patients (i.e., AD and/or MCI patients with illness severity) separately from those obtained studying homogeneous groups of patients (i.e., only mild AD or only amnesic MCI). This was done to keep separate data in which the presence of more severe patients (e.g., severe AD) could bias results and to investigate whether a specific pattern of callosal degeneration was associated with different illness stages (from amnesic MCI to mild, moderate and severe AD). Thus, using the MRI modality as a starting point, we reviewed an extensive body of literature focusing mainly on structural neuroimaging (i.e., ROI and VBM) and quantitative parametric mapping (i.e., diffusion-weighted imaging (DWI) and DTI).

Initially, 52 studies were selected as potential candidates for review. Studies were included if they: 1) were brain structural MRI studies published from January 1997 to March 2009; 2) compared AD or MCI patients with a HC group; and 3) were published in the English language. We also hand-searched relevant journals and inspected the bibliographies of all major articles to find other relevant publications. Historically important and conceptually related articles were included as well. One study was excluded from the review [53] because it did not compare AD patients with a $\mathrm{HC}$ group. Concerning the nomenclature of the CC subregions, to be consistent across studies we refer to 


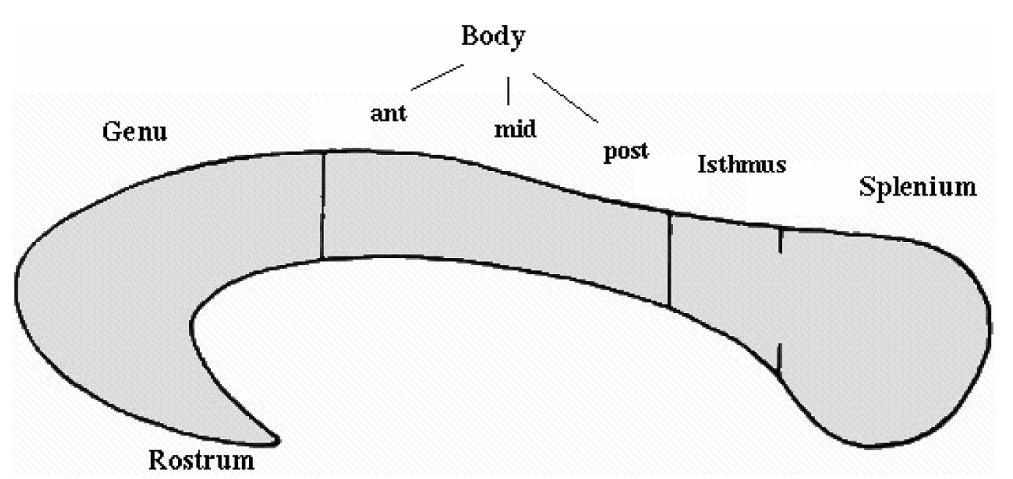

Fig. 1. Schematic view of corpus callosum for nomenclature. The image shows the different subregions of the CC regardless of splitting method and callosal fiber topography.

the different subregions of the $\mathrm{CC}$ as follows: rostrum, genu, body (split into anterior, mid, and posterior), isthmus, and splenium (see Fig. 1 for a schematic view).

\section{REGION OF INTEREST STUDIES}

Early morphometric MRI studies of the CC in AD quantified atrophic changes using ROI analysis. In general, to perform a ROI analysis a high spatial resolution $3 \mathrm{D}$ brain sequence has to be acquired with an isotropic voxel (e.g., $1 \times 1 \times 1 \mathrm{~mm}^{3}$ ), so that all three orthogonal planes can be inspected. This procedure also facilitates identification of anatomical landmarks for selection of the ROI. To obtain a better identification of the CC ROI, each MRI brain volume is usually positioned along the anterior-posterior commissure line. This is particularly important for obtaining a reliable measure of the $\mathrm{CC}$, because it is sampled from its most medial part on a $1 \mathrm{~mm}$ thick slice. Each ROI is identified by its landmarks and manually mapped. Then the voxels belonging to the ROI are colored to show the volume of the $\mathrm{CC}$ in $\mathrm{mm}^{3}$. According to the model used, an automatic procedure is applied to split the CC. To determine the size of the $\mathrm{CC}$, several methodologies have been proposed for measuring its midsagittal surface area and regional divisions. In Fig. 2, we report the most frequently used methods. Finally, to reduce inter-individual variability in gross brain size, different reference measures, such as forebrain volume, cranial capacity, cross-sectional cerebral area, or normalization of the MRI brain volumes into the Talairach proportional stereotaxic space, are used either as a ratio $[54,55]$ or as a covariate in the statistical model $[56$, 57]. In this way, gross brain size differences are ruled out.
ROI analysis is considered a robust, well-validated technique. However, it requires operator skills to define the boundaries of the structures to be investigated. Furthermore, it is time consuming, because the researcher has to draw the ROI manually, and allows studying only a limited number of anatomical regions chosen a priori.

Numerous ROI studies have investigated callosal changes in AD patients [7,10-12,14-19,24,25,27,28, $31,38,42,43]$. Overall, these studies report a reduction of the total callosal area, specifically of the rostrum, genu, anterior body, isthmus, and splenium of the CC. It should be noted that the vast majority of these studies included $\mathrm{AD}$ patients with illness stages, ranging from mild to severe dementia (hereafter called AD "all stages"). Only a few studies investigated patients with fewer heterogeneous clinical features, such as those affected by mild or moderate $\mathrm{AD}$, and they reported discrepant results. More specifically, while some studies on mild AD found atrophy in the posterior callosal subregions (isthmus and splenium) $[9,11,13,19]$, others found no atrophy in callosal regions [45,58]. As far as we know, there is only one study [59] on moderate $\mathrm{AD}$ patients that describes a reduction of the anterior body, mid body, and isthmus in AD patients compared with HC. Likewise, inconsistent results have been reported in studies on subjects with MCI. In a study on amnesic MCI, Wang and colleagues [9] found atrophy in posterior subregions (isthmus and splenium). Yet, another research group [46] found no callosal changes when patients with amnesic MCI were compared with HC. By contrast, Thomann and coworkers [10] reported a reduction in the anterior subregion (rostrum, genu, anterior body) of the $\mathrm{CC}$ in a group of MCI patients with different cognitive subtypes (amnesic and multidomain amnesic, hereafter called MCI "all subtypes") using the ROI approach. Finally, Hallam et al. [43] re- 


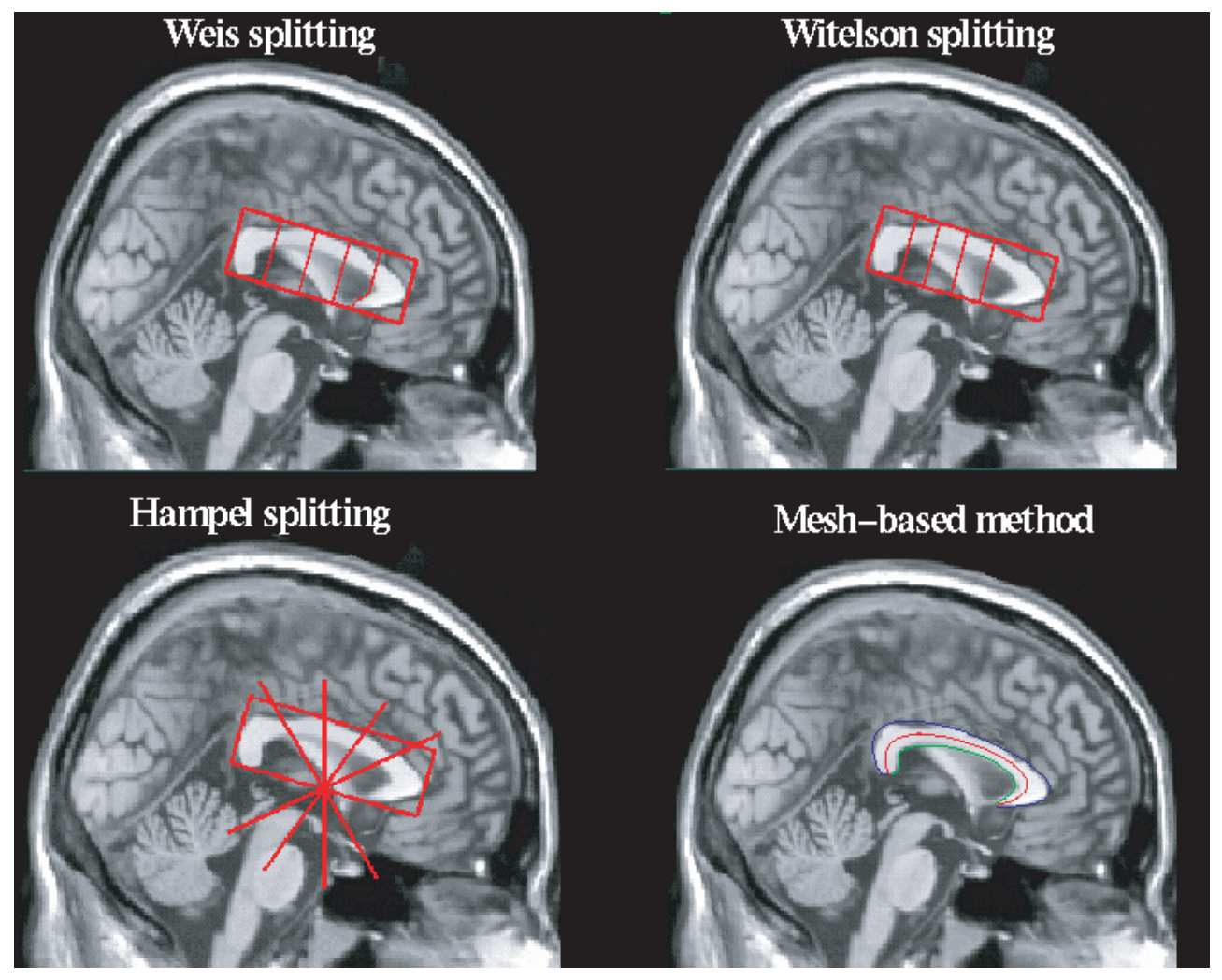

Fig. 2. Different corpus callosum manual tracing. In Weis splitting, the midsagittal slice of the CC is split into five distinct sectors of equal size along a line joining the most anterior and posterior points of the genu and splenium, respectively. Subregions are the following: $\mathrm{CC} 1=$ rostrum and genu, $\mathrm{CC} 2=$ rostral body, $\mathrm{CC} 3=$ midbody, $\mathrm{CC} 4=$ isthmus, $\mathrm{CC} 5=$ splenium. In Witelson splitting, the midsagittal slice of the $\mathrm{CC}$ is split into five distinct sectors of different percentages: $33 \%, 17 \%, 17 \%, 13 \%, 20 \%$ respectively. The subregions are: $\mathrm{CC} 1=$ rostrum, genu and anterior body, $\mathrm{CC} 2=$ midbody, $\mathrm{CC} 3=$ caudal body, $\mathrm{CC} 4=$ isthmus, $\mathrm{CC} 5=$ splenium. In Hampel splitting, the midsagittal slice of $\mathrm{CC}$ is split into five distinct sectors of equal percentage (36\%) along a line joining the most anterior and posterior points of genu and splenium respectively. The subregions are: $\mathrm{CC} 1=$ rostrum, $\mathrm{CC} 2=$ anterior truncus, $\mathrm{CC} 3=$ middle truncus, $\mathrm{CC} 4=$ posterior truncus, $\mathrm{CC} 5=$ splenium. In the Mesh-based method, there is no splitting. Upper and lower callosal boundaries are manually outlined in the midsagittal section. Then, the spatial average from 100 equidistant surface points representing the upper and lower boundaries is calculated. The result is a new midline segment (the spatial average), also consisting of 100 equidistant points. Finally, the midline segment is quantified, so that it corresponds to CC thickness.

ported no difference between a mild ambiguous group (i.e., with a cognitive profile similar to that of multidomain MCI) and $\mathrm{HC}$.

Recently, our group [21] applied a well-validated structural analysis technique, that is, the computational mesh-based method, to map callosal thickness [60-63] and to study the CC changes in three distinct homogeneous groups of patients with mild $\mathrm{AD}$, severe $\mathrm{AD}$, and amnesic MCI compared with HC. The main finding of our study was reduced thickness in the callosal genu, anterior body, and splenium in severe AD patients compared with $\mathrm{HC}$. The callosal reductions in the milder and pre-clinical stages of AD appeared to be less pronounced (i.e., they were more restricted spatially). When mild AD patients were compared with $\mathrm{HC}$, we observed reduced callosal thickness within the callosal anterior third, as well as at the border between the anterior third and the anterior body. When amnesic MCI patients were compared with $\mathrm{HC}$, reduced callosal thickness was found in the callosal posterior body and within the splenium near the callosal posterior end. Nevertheless, group differences between mild AD and amnesic MCI subjects and healthy controls were not confirmed by permutation testing (see Table 1 for technical details of the study).

\section{VOXEL-BASED MORPHOMETRY STUDIES}

After the ROI studies, a new imaging technique, VBM, was adopted to examine CC changes [64]. VBM is increasingly used to investigate differences in brain 
morphology among groups. Indeed, it provides an estimate of inter-group differences in GM and WM density and/or volume on a voxelwise basis in a standardized space. The VBM protocol has been somewhat changed in the last few years to improve the preprocessing steps. In its previous version, called the "Optimized VBM" protocol, running in the framework of Statistical Parametric Mapping (SPM99, SPM2, Wellcome Department of Imaging Neuroscience, University College London, London, UK), a customized GM template is created and subsequently used to normalize all structural images to the stereotaxic MNI space. To create the customized GM template, all images (patients and controls) are first spatially normalized (12-parameter affine and $6 \times 8 \times 5$ basis functions) using the standard MNI template in SPM99 or SPM2. Then each normalized image is segmented into GM, WM, and cerebrospinal fluid (CSF). The normalized and segmented GM images are smoothed (isotropic kernel, usually with a FWHM between 8 and $12 \mathrm{~mm}$ ) and averaged to create the customized GM template. Then all the original MR images in native space are segmented into GM, WM and CSF. The GM and the WM images are normalized to the customized GM template and the deformation parameters obtained from this are applied to all original images. This provides optimally normalized whole-brain images, which are segmented again into GM, WM, and CSF. Finally, all GM and WM images are modulated or not (to assess the absolute amount or concentration of a region of tissue [34] and smoothed with an FWHM kernel (the smoothing conforms the data more closely to the Gaussian field model underlying the statistical procedures used for making inferences about regionally specific effects). Smoothing also has the effect of rendering the data more normally distributed (by the central limit theorem). The intensity of the smoothed data in each voxel is a locally weighted average of GM density from a region of surrounding voxels; the size of the region is defined by the size of the smoothing kernel [64].

Although the current procedure is somewhat different from the original one, the logic of image preprocessing is the same. Briefly, in the unified segmentation step [65], implemented in the framework of Statistical Parametric Mapping (SPM5, Wellcome Department of Imaging Neuroscience, University College London, London, UK), images are normalized and segmented into GM and WM partitions and into CSF. For each subject, normalized segmented GM and WM are modulated or not and smoothed with a Gaussian Kernel (FWHM). In Fig. 3, we show a flow chart of Optimized VBM image processing.
Compared with ROI analysis, VBM analysis has the advantage of being a spatially specific and unbiased method for analyzing MR images. It is completely operator independent and provides a quantitative measure of the regional GM and WM volume or density at a voxel scale throughout the whole brain without choosing any a priori ROI [34,64].

The first VBM study on WM in moderate AD [66] reported the presence of diffuse atrophy within the $\mathrm{CC}$ but did not mention its specific location. Later works on AD "all stages" groups (more precisely on mild to moderate patients) reported conflicting results. Thomann et al. [10] found a significant loss of callosal volume in the anterior portion of the CC (rostrum, genu, and anterior body). Chaim and colleagues [8] reported a reduction in almost all subregions of the CC (genu, anterior and posterior body, isthmus, splenium), but mainly in the left hemisphere. Li et al. [42] found a reduction limited to the posterior CC subregions (isthmus and splenium), and, in agreement with Chaim et al. [8], prevalently on the left side of the CC.

We found only one VBM study [10] on callosal changes in MCI. However, it did not report differences in the CC in MCI subjects compared with $\mathrm{HC}$.

In our study [20], we applied the VBM technique to study $\mathrm{CC}$ changes in patients with mild $\mathrm{AD}$, severe $\mathrm{AD}$, and amnesic MCI. We found atrophy in severe $\mathrm{AD}$, specifically in the genu, anterior body, and splenium of the CC. Patients with mild AD presented a reduction in both the anterior and posterior $\mathrm{CC}$, and those with amnesic MCI only in the anterior CC. Nevertheless, the results obtained on patients with mild $\mathrm{AD}$ and amnesic MCI were not supported by statistical correction for multiple comparisons. Recently, however, we replicated the study on a larger sample of patients with mild AD and amnesic MCI [21] and found a significant WM density reduction in the genu and splenium of the $\mathrm{CC}$ in patients with mild AD. In patients with amnesic MCI compared with $\mathrm{HC}$, we found a reduction only in the genu of the CC (see Table 2 for technical details of the study).

\section{DIFFUSION-WEIGHTED IMAGING AND DIFFUSION TENSOR IMAGING STUDIES}

Diffusion imaging is a non-invasive MR technique adopted to study aspects of WM anatomy. It uses local water diffusion in the tissues as the starting point. Although the determinants of water diffusion in WM tissues are still not completely understood, there is 


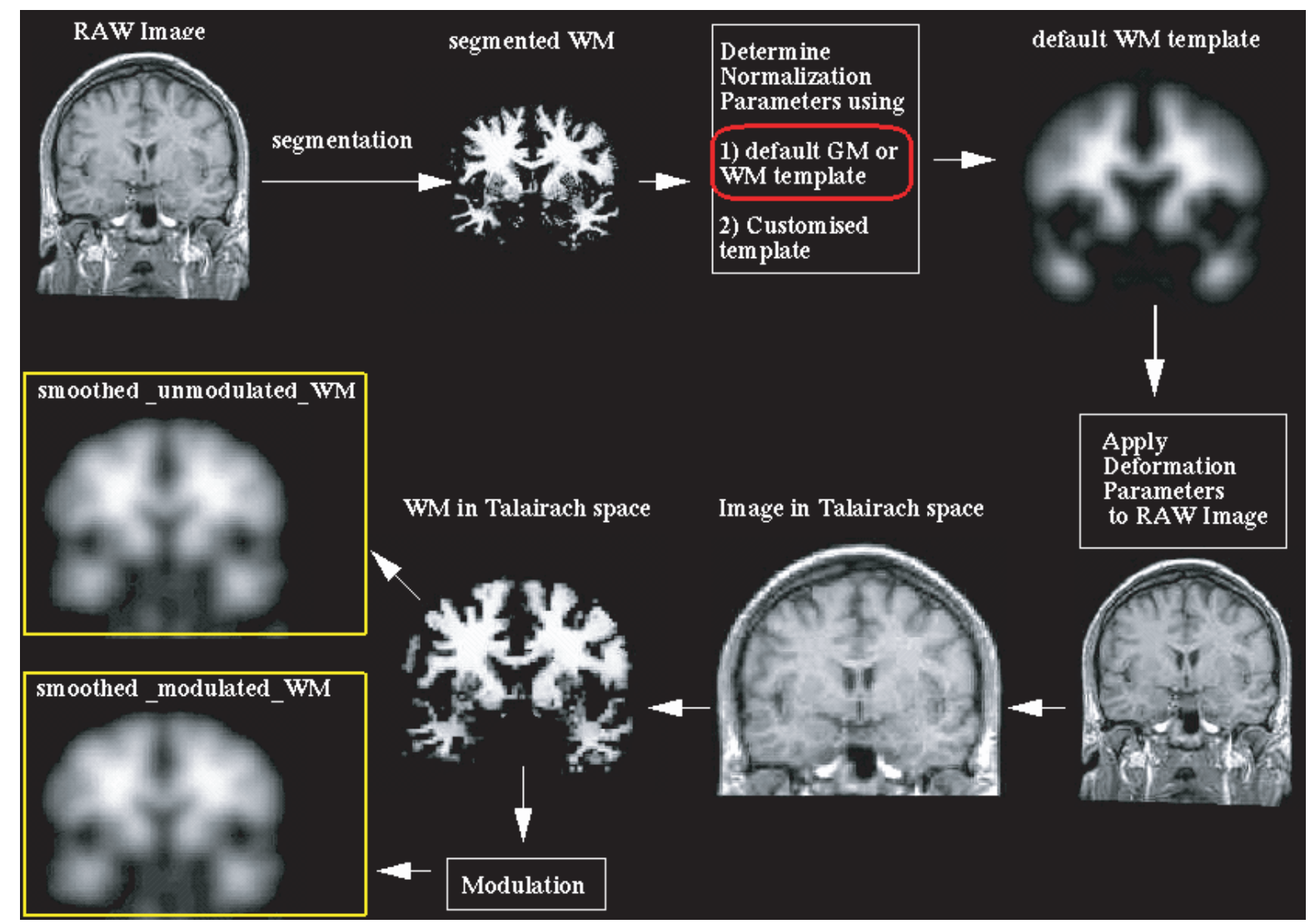

Fig. 3. Optimized Voxel-based Morphometry pipeline. Image shows the spatial processing steps of optimized VBM and the two resulting analyses. Templates used for normalization (gray matter or white matter) are indicated in red and the two analyses are indicated in yellow. Both affine and nonlinear basis function normalization are used in the technique.

general agreement that the physicochemical properties of the tissue (e.g., viscosity and temperature) as well as its structural components (macromolecules, membranes, and intracellular organelles) can substantially affect water diffusivity. In other words, diffusivity of water depends primarily on the presence of microscopic structural barriers in tissues that can alter the random motion of water molecules. Membranes of cell bodies, axons, and myelin sheaths randomly impede the movement of water in the brain tissue, facilitating diffusion of water molecules preferentially along their main direction. Such preferentially oriented diffusion is called anisotropic diffusion. DWI is a one-dimensional technique, that is, it is used to measure the projection of all molecular displacements along one direction at a time. Therefore, it is sufficient to apply diffusion gradients along only one direction. As DTI is a three-dimensional technique, diffusion gradients must be applied along at least six noncollinear, non-coplanar directions in order to obtain enough information to estimate the six independent elements of the diffusion tensor (D) (in [67]).
In general, apparent diffusion coefficient (ADC), $\mathrm{MD}$, and FA have been used as the main diffusivity parameters. Although ADC measures the magnitude of water diffusion, it only provides a measure of the displacement of molecules in one direction; $\mathrm{MD}$ is a measure of the average motion of water molecules, independent of tissue directionality; and FA measures the directionality of water diffusion.

ADC, MD, and FA may be altered by changes caused by the pathological process of AD. Pathological disruption of cell membranes and loss of myelin and axonal processes should lessen the restrictions on water movement. Therefore, the diffusivity measured with ADC or with MD should increase. Furthermore, the loss of tissue organization should also cause a decrease in anisotropy (FA). It is assumed that reduced water diffusion parallel to axonal tracts or FA is indicative of axonal degeneration and that increased water diffusion perpendicular to axonal tracts or MD is associated with changes in water content, disruption, and partial break- 


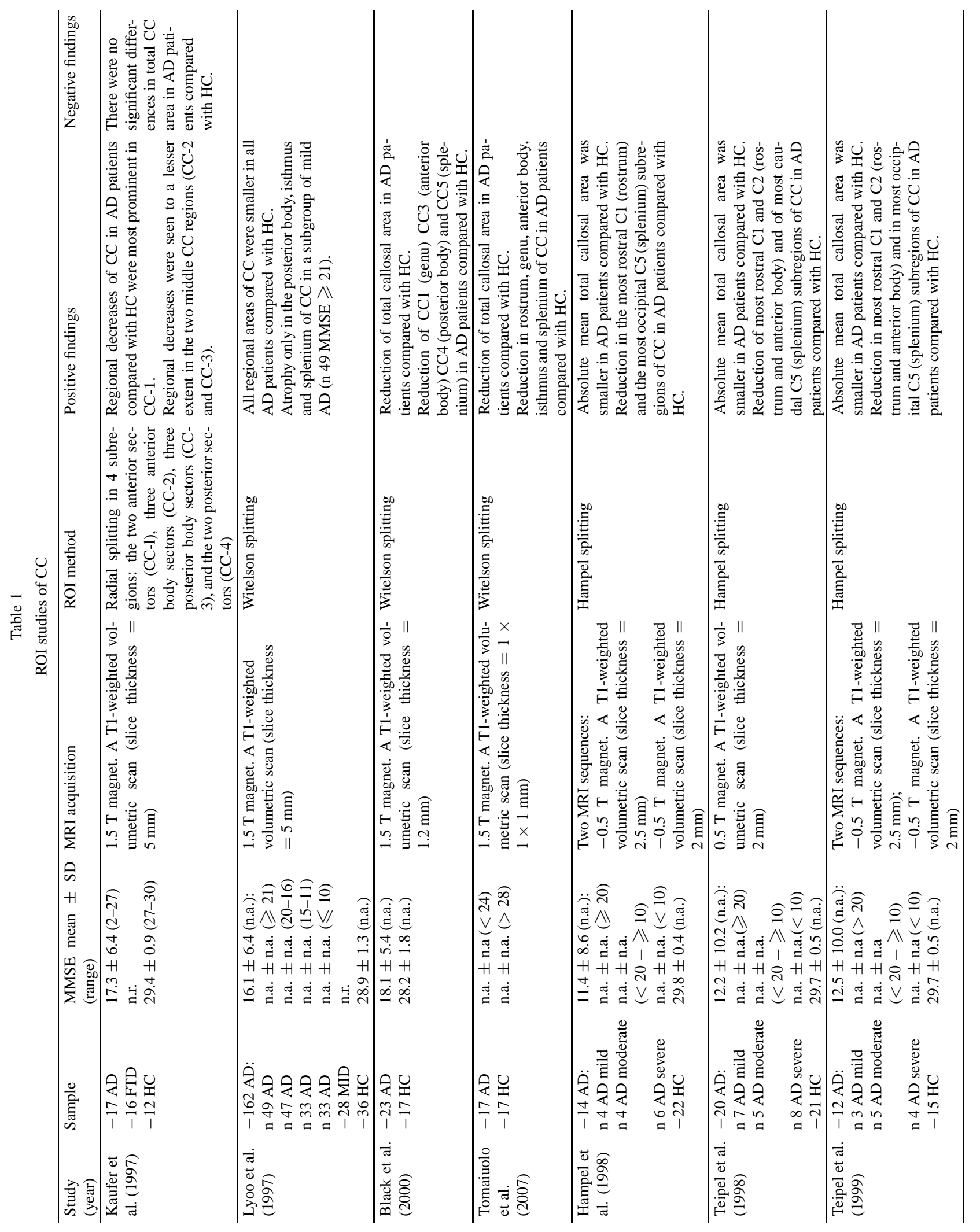




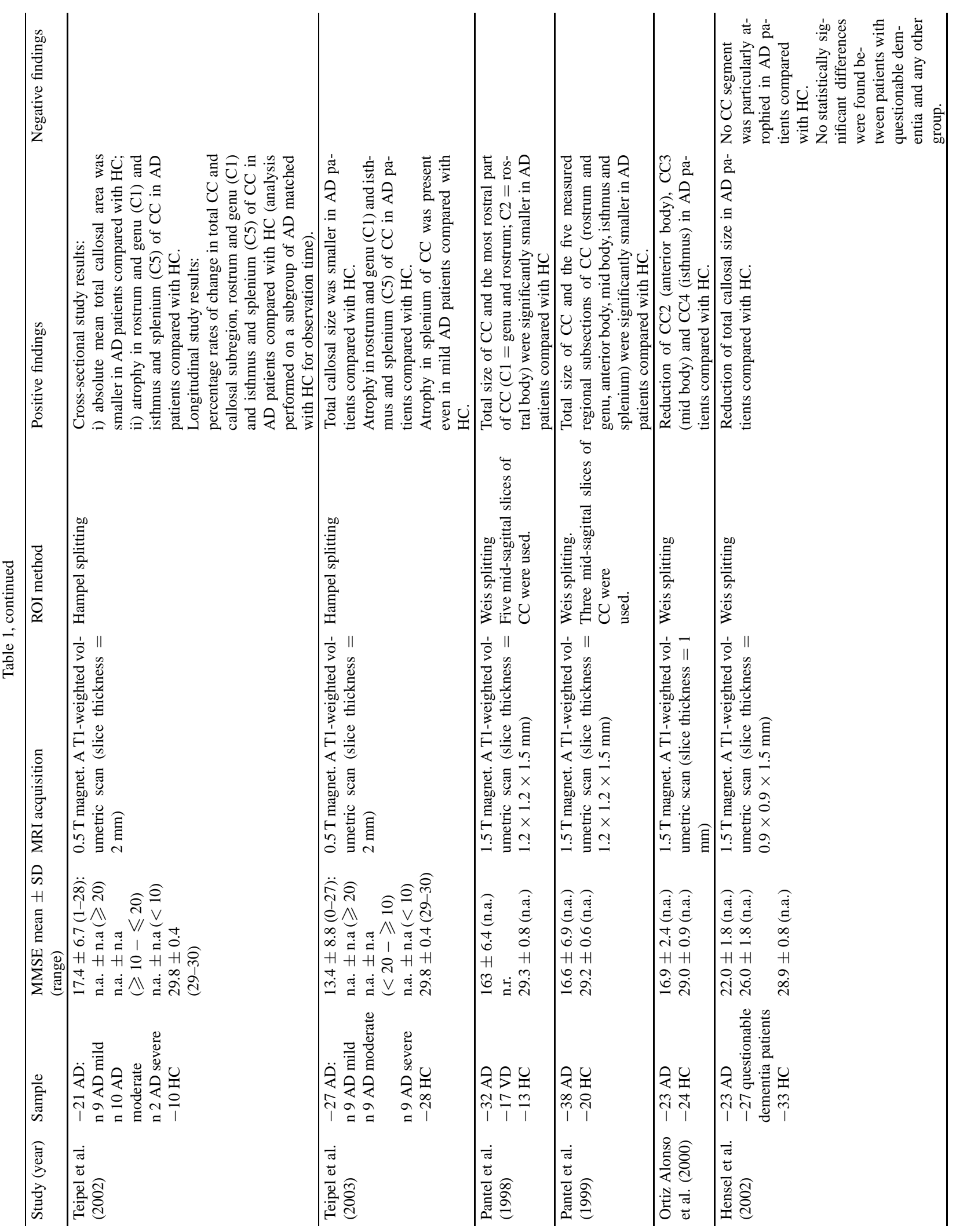




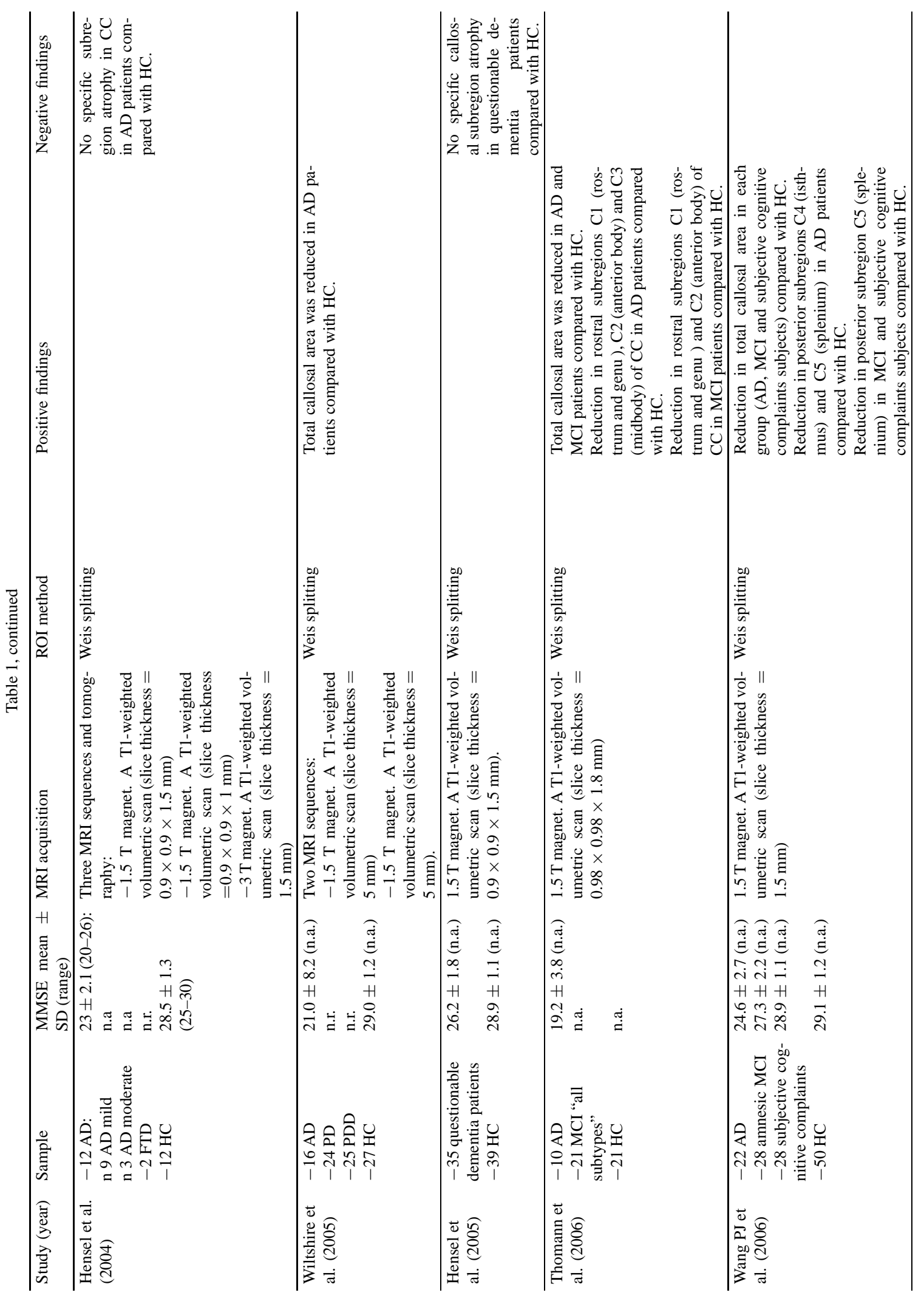




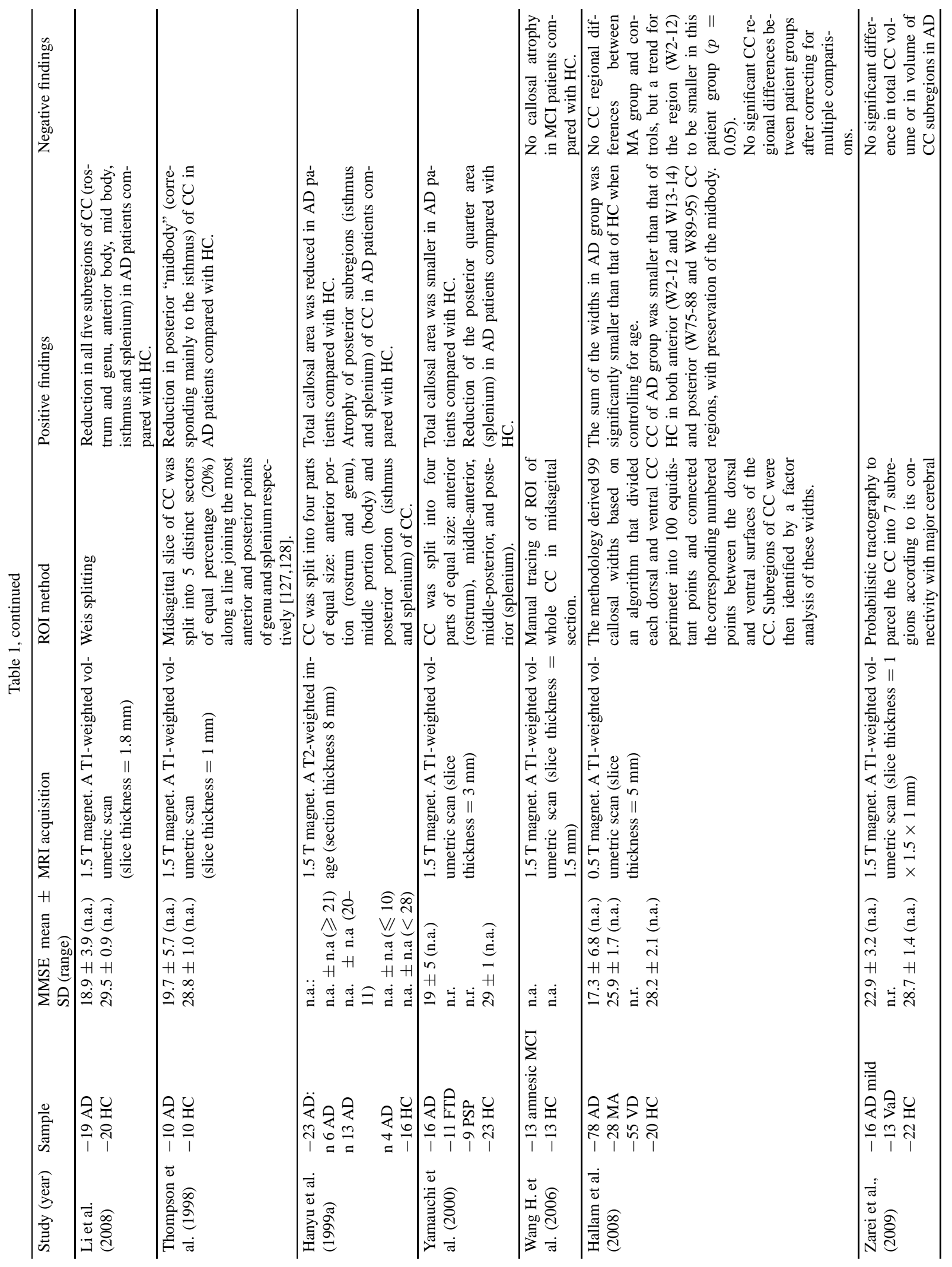




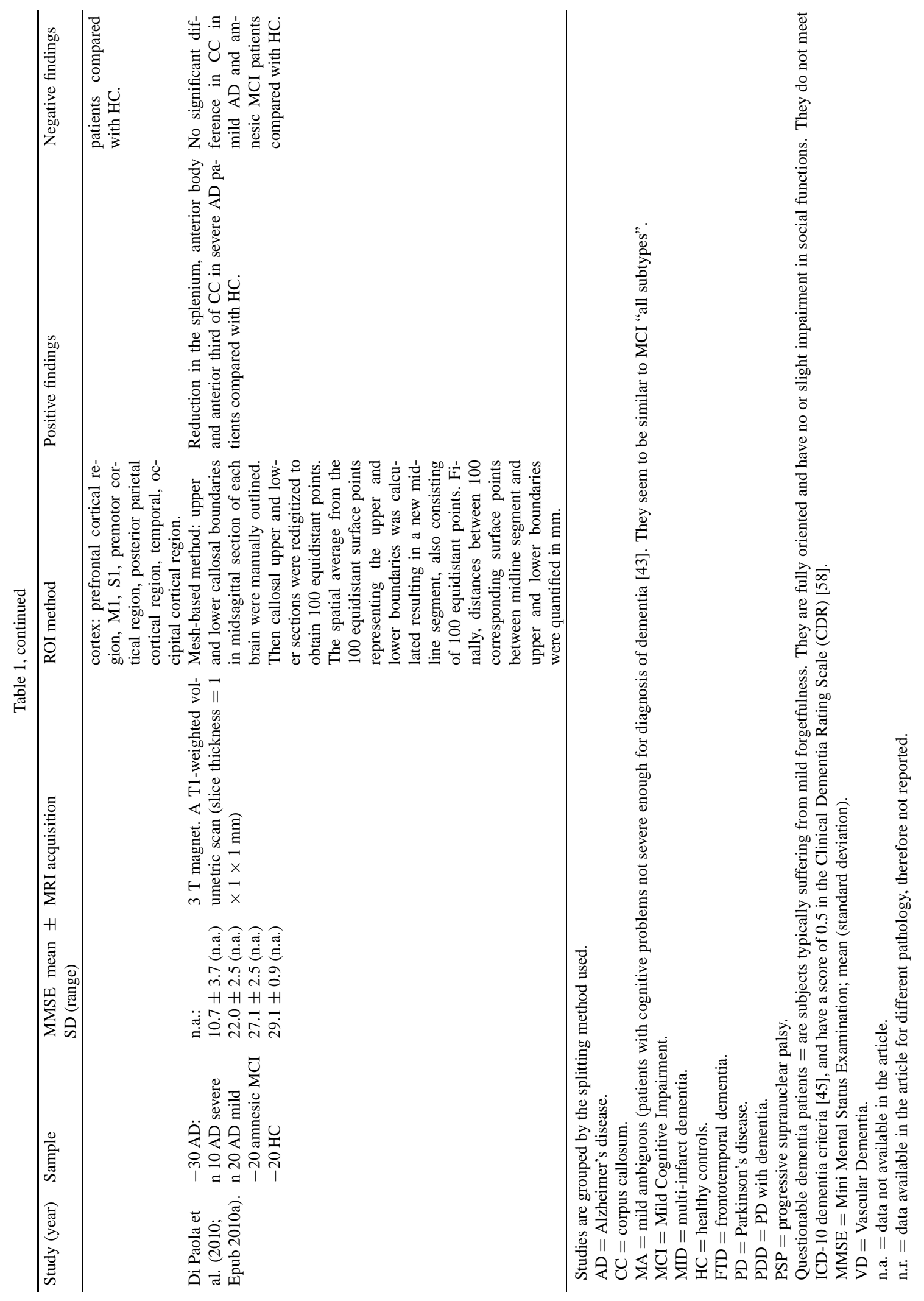




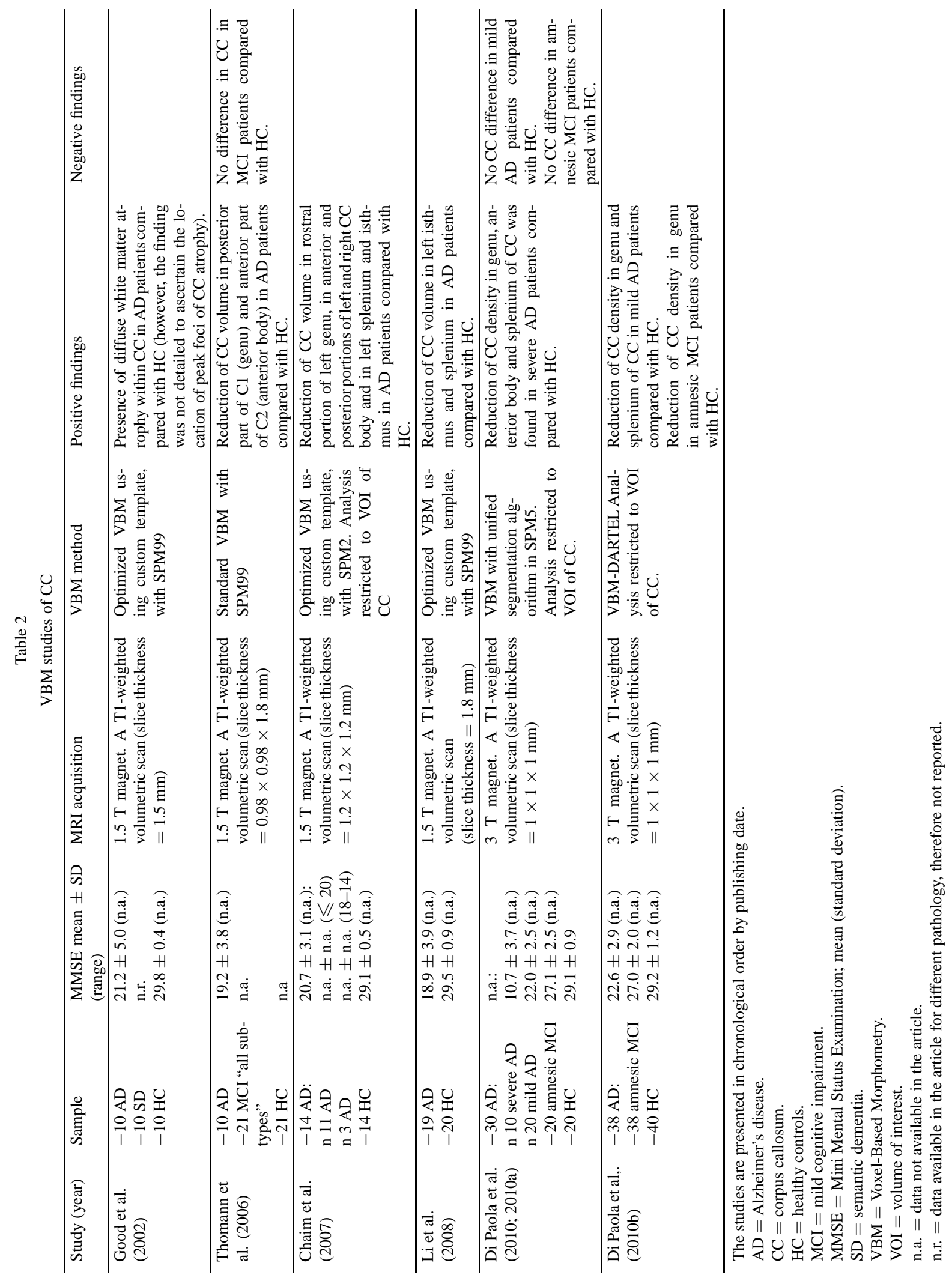




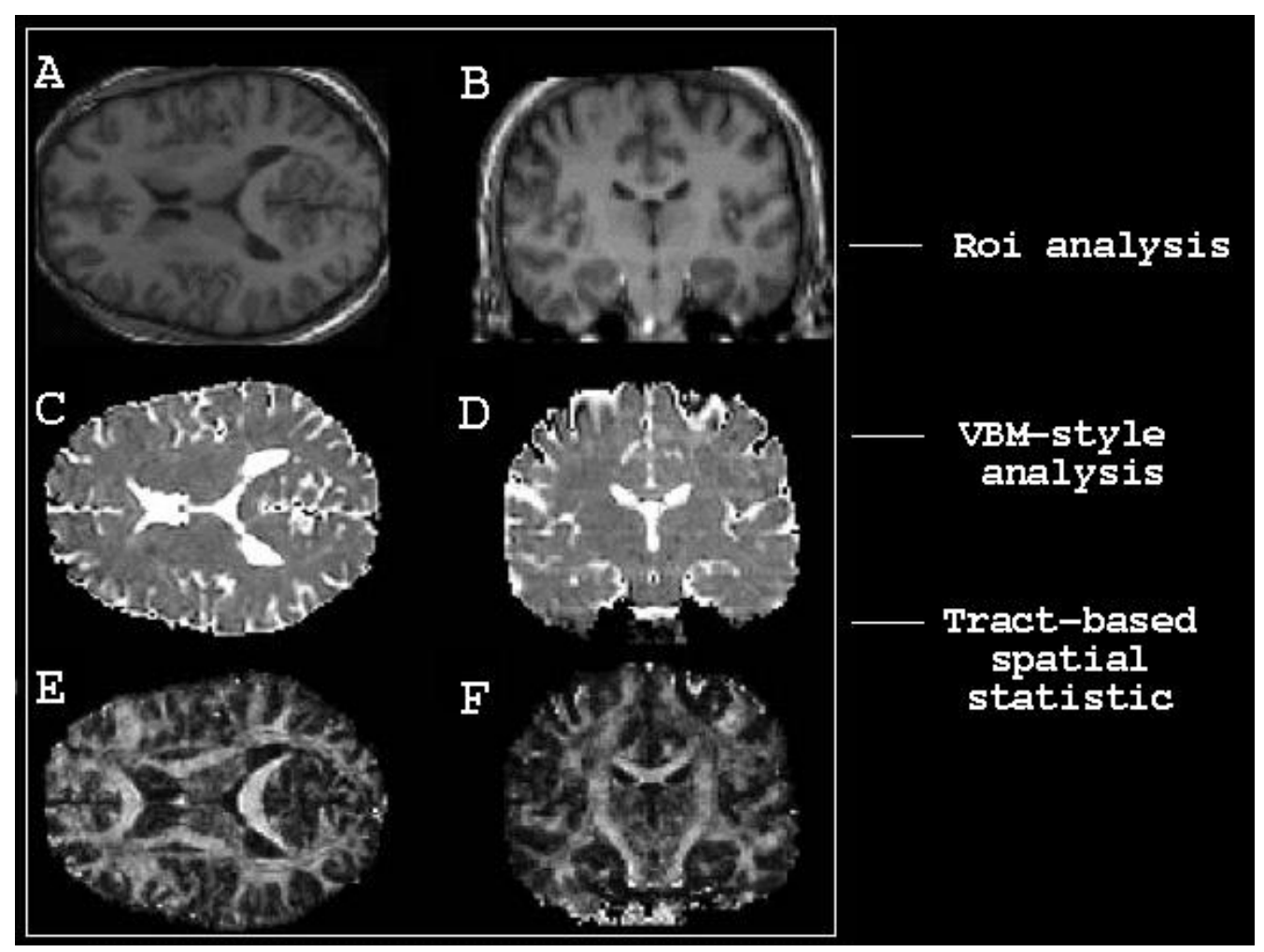

Fig. 4. Diffusion tensor-based images. A and B show axial and coronal T1-weighted anatomical images. C and D trace ADC maps (mean diffusivity) of the same slices shown in A and B. E and F are fractional anisotropy maps showing high contrast between gray and white matter. Once the mean diffusivity and fractional anisotropy maps are calculated, there are three approaches for post processing: manual ROI, VBM-style analysis [64] and tract-based spatial statistics (TBSS) [122].

down of tissue cytoarchitecture [68,69], sclerosis [70], or demyelinating processes [71-74]. Recently, Choi and colleagues [75] began investigating other measures of diffusion, such as radial diffusivity (DR) and axial diffusivity (DA), to determine whether differences in anisotropy are caused by diffusion perpendicular or parallel to the WM fibers, respectively. The assumption, arising out of experiments on animal models, is that significantly reduced DR in WM without differences in DA might represent specifically compromised integrity of myelin in the absence of axonal structural irregularities.

With respect to structural MRI (ROI and VBM), DWI and DTI techniques have the advantage of being very sensitive in detecting microstructural abnormalities not revealed by other volumetric measures $[28,76]$. In fact, structural MRI techniques, which reflect macrostructural changes, may not be sensitive to the degeneration of myelin and axons in the WM microstructure $[28,46]$. On the contrary, DWI and DTI parameters have been applied in CC studies and have demonstrated much greater sensitivity in revealing the WM degeneration in
AD than conventional MRI imaging techniques $[68,71$, 77].

DWI studies on AD “all stages" patients [30,33] report no significant group differences in measurements of the anisotropy index (AI) - calculated by dividing the ADC perpendicular to the prominent callosal fiber direction by the ADC parallel to the predominant fiber direction of the $\mathrm{CC}$ - within the genu and splenium of the CC. On the other hand, Hanyu et al. [28,29] using the same type of AI (that the authors called ADC ratio) found a decrease in the anterior (rostrum and genu) and posterior (isthmus and splenium) CC of AD "all stages" patients. Also, Wang and collaborators and Ray and colleagues $[46,78]$ found a higher ADC in the CC of patients with amnesic MCI than in HC.

DTI studies on AD "all stages" patients [32,35,36, $39,41,79,80$ ] basically found changes in the anterior (genu) and posterior (splenium) subregions of the CC in AD patients compared with HC. More specifically, Rose et al. [32] found a value reduction in the splenium of AD patients but not in HC. They used lattice index (LI) as a measure of anisotropy. LI is an intervoxel 
measurement of diffusion anisotropy that exploits information about the orientation coherence of the eigenvectors of diffusion tensor in adjacent voxels, to improve the estimate of diffusion anisotropy within a reference voxel. It is especially immune to background noise in the DW images and provides a quantitative, robust measurement of diffusion anisotropy [81].

The other studies that measured MD and/or FA can be separated into those which found mainly an increase of MD and/or a decrease of FA in the posterior subregion (splenium) of the $\mathrm{CC}$ in $\mathrm{AD}[35,36,41,79,80]$ and those which reported an increase in MD or a decrease in FA in the anterior subregions (genu and anterior body) of $\mathrm{CC}$ in $\mathrm{AD}$ compared with $\mathrm{HC}[35,39]$. It is very difficult to summarize the general picture of these results because other studies on AD "all stages" [23,37, $40,75]$ reported no significant differences in MD or FA in the anterior and posterior $\mathrm{CC}$ when the patient group was compared with HC. Stahl and coworkers [40] also measured ADC and relative anisotropy and found no differences between AD patients and HC. Furthermore, the findings of studies on more homogeneous patients, such as those with mild AD, are discrepant. For example, Xie et al. [82] found a decrease of FA in the genu and left anterior body of the CC, whereas Ulkmar et al. [83] found a decrease of FA in the genu and splenium of the CC; other studies [84-87] found no differences in the $\mathrm{CC}$ in patients with mild AD.

At present, the DTI study results on MCI patients can be divided into two groups: 1) DTI studies on both amnesic and MCI "all subtypes" [23,40,41,84,85,88] that found no differences in MD and/or in FA in the CC compared with $\mathrm{HC}$; and 2) the most recent studies [83, 86,89-91], which reported differences. One study on MCI "all subtypes" [89] found a significant change in $\mathrm{MD}$ and FA in the genu and the splenium of the CC in patients compared with HC. Moreover, studies on amnesic MCI $[83,86,90]$ mainly found a decreased FA and/or increased MD value in the splenium of the CC. Wang and colleagues [91] also reported a decreased FA value in the genu and the splenium and increased ADC in the genu of the CC (see Table 3 for technical details of the study). In our study [21], we found reduced FA in the genu and anterior body of the CC, increased $\mathrm{DA}$ in the body and in the posterior subregions of the $\mathrm{CC}$, and increased DR in the entire $\mathrm{CC}$ in patients with mild AD compared with $\mathrm{HC}$. We found no significant differences in the $\mathrm{CC}$ in patients with amnesic MCI compared with $\mathrm{HC}$.

\section{DISCUSSION}

The purpose of this review was to summarize CC changes in patients with $\mathrm{AD}$ and MCI with regard to different illness stages and the measurements used to calculate the modifications. Regardless of the technique used (i.e., ROI, VBM, DWI, or DTI), the main result in $\mathrm{AD}$ patients across all studies when severity of illness was not taken into consideration (AD "all stages") was primarily a change in the anterior (genu and anterior body) and posterior (isthmus and splenium) regions of the $\mathrm{CC}$ (see Table 4). This finding is less consistent when patients are separated into more homogeneous groups (e.g., mild AD and amnesic MCI). Indeed, some studies reported changes in the anterior subregion (e.g. [20,21,46,82]), some in the posterior subregion $[20,21,83,91]$, and some found no callosal changes $[40,85,92]$. This inconsistency in results may be the consequence of reduced sample size of studies considering discrete diagnostic categories of different clinical stages. But, whatever the reason, little is known about how early callosal atrophy occurs in AD and whether this change is already detectable in patients at higher risk of developing the disease, such as those with amnesic MCI [51] (see Table 4).

\section{Region-specific callosal reduction}

In summary, callosal atrophy in AD "all stages" affects the posterior and anterior subregions and spares the body of the CC. Therefore, the CC atrophy found in AD "all stages" groups corresponds with previously reported cortical areas considered to be involved in AD pathology [93]. The posterior subregion (splenium and isthmus) subserves two-thirds of the higher-order processing areas of the lateral temporal and parietal lobe, which, together with the mesial temporal structures [94], are primarily involved in cortical AD degeneration $[93,95,96]$. This could interfere with functioning of the posterior cortical memory networks, which subserve episodic memory operations and are impaired early in AD patients [97]. On the other hand, the anterior portion (genu and anterior body) is responsible for the inter-hemispheric connection between the prefrontal association cortices $[87,98,99]$, that is, the regions involved in the later stages of AD pathology evolution $[93,95,96]$ and implicated in monitoring information in working memory and in the active retrieval of information from posterior cortical association areas [100-102]. Thus, the volume reduction in these 
M. Di Paola et al. / Corpus Callosum in AD and MCI

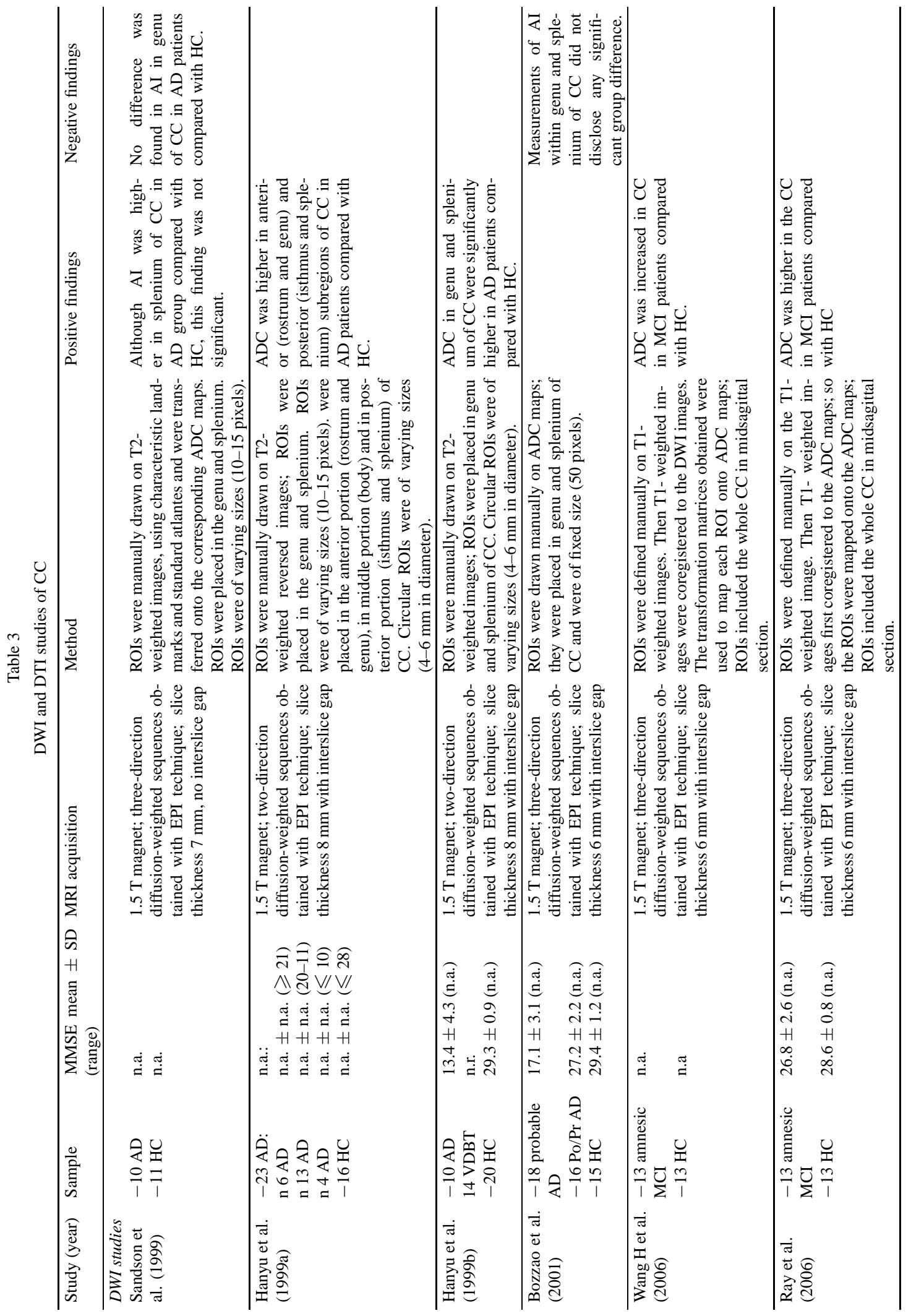




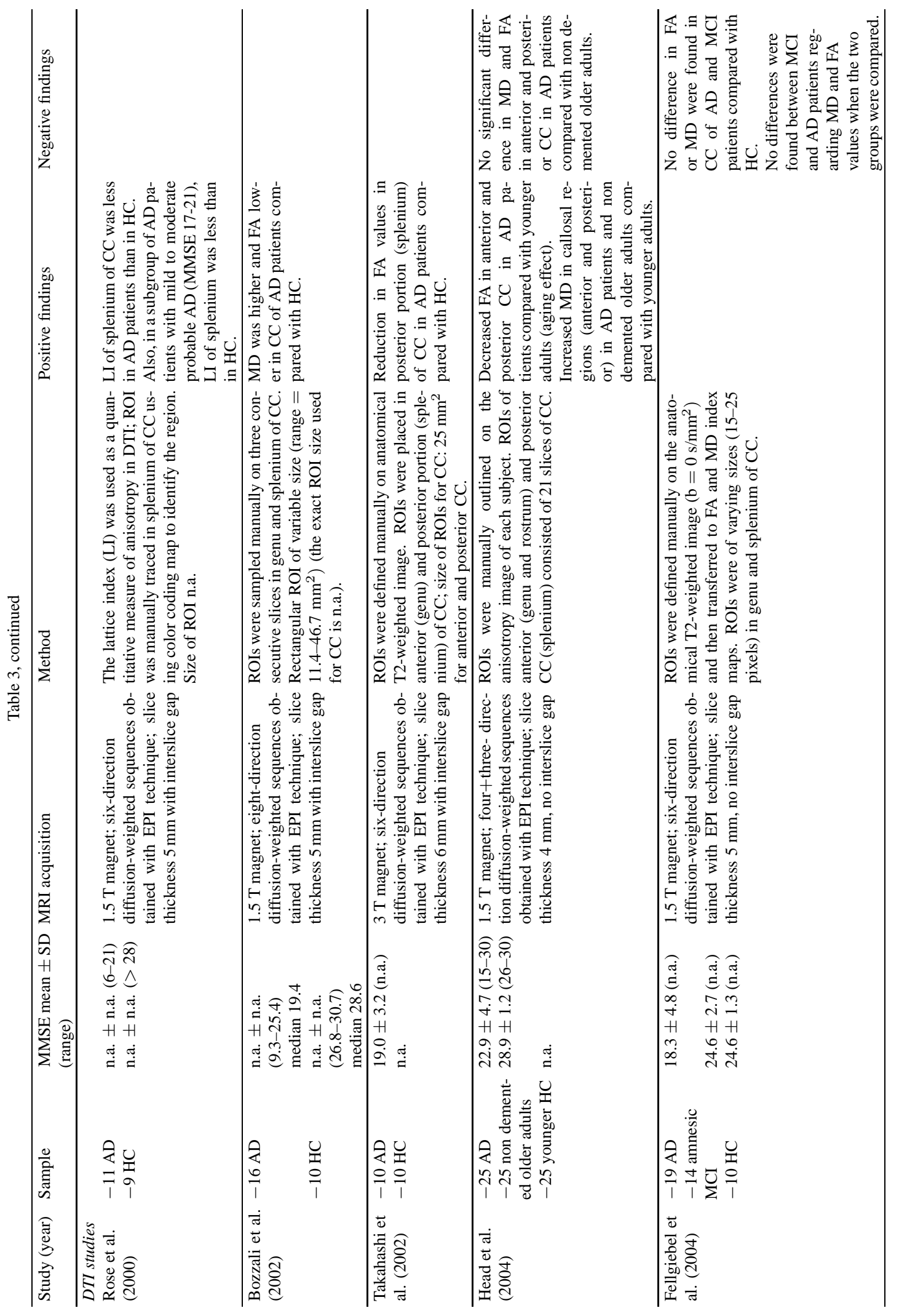




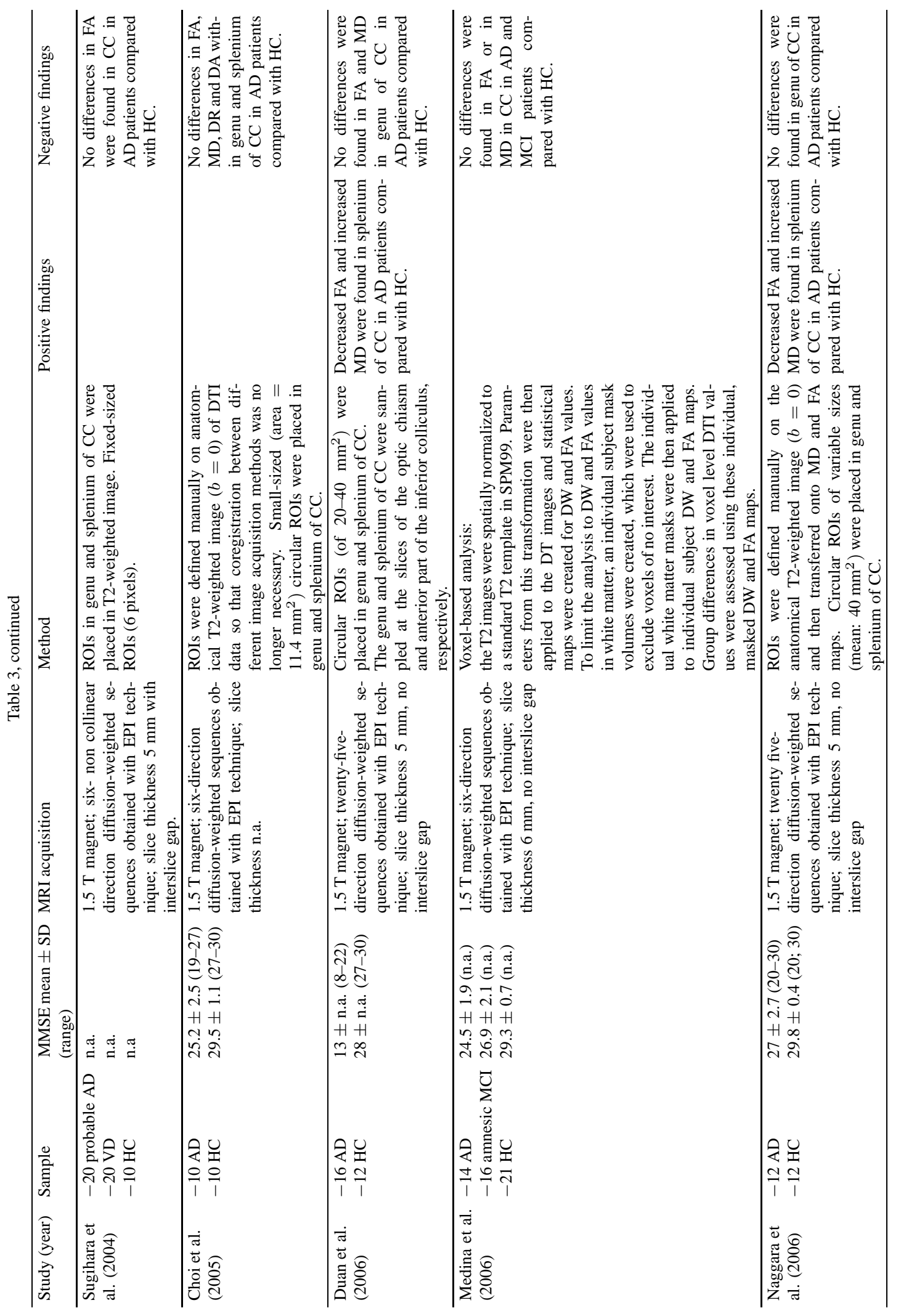




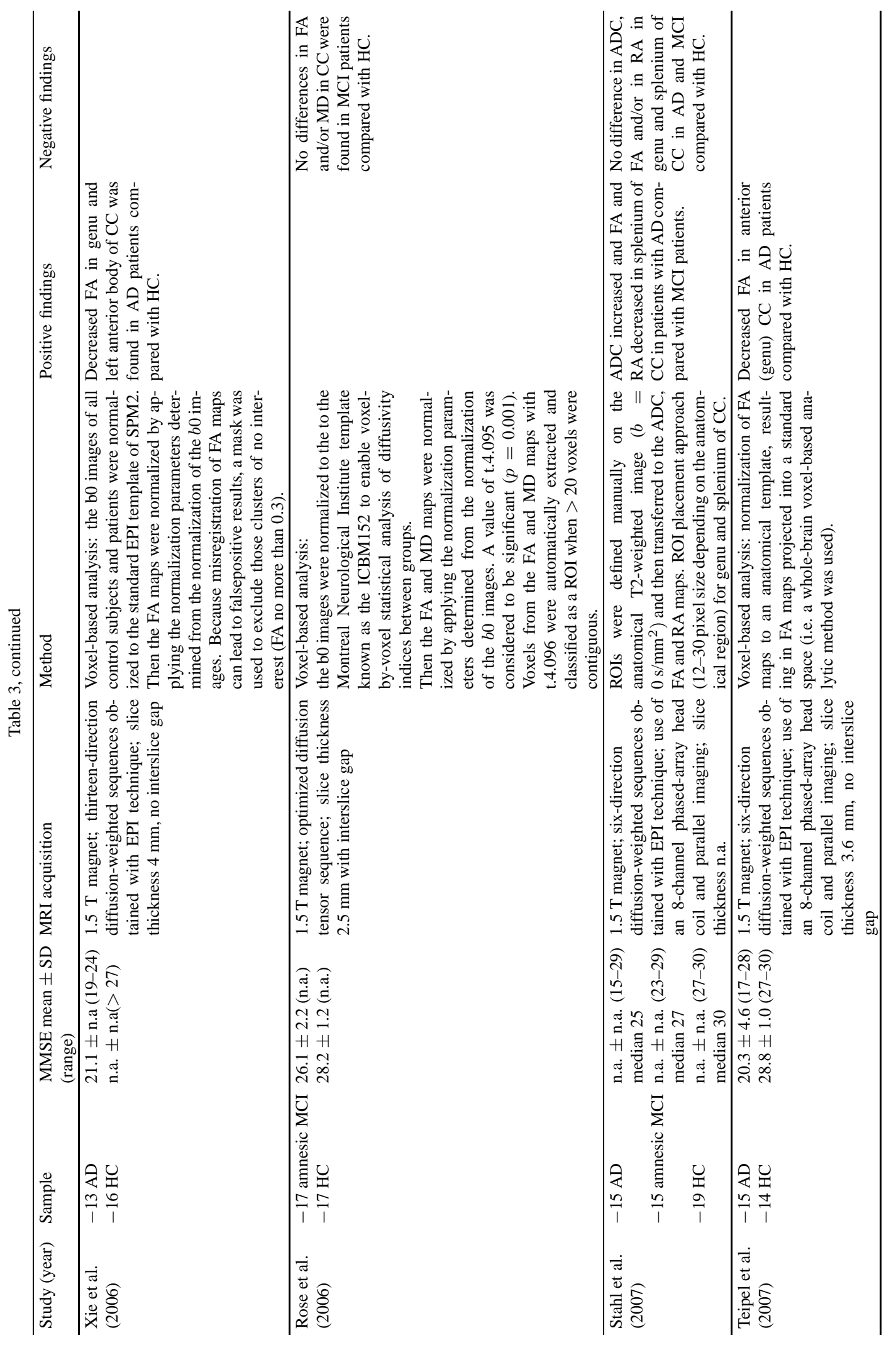




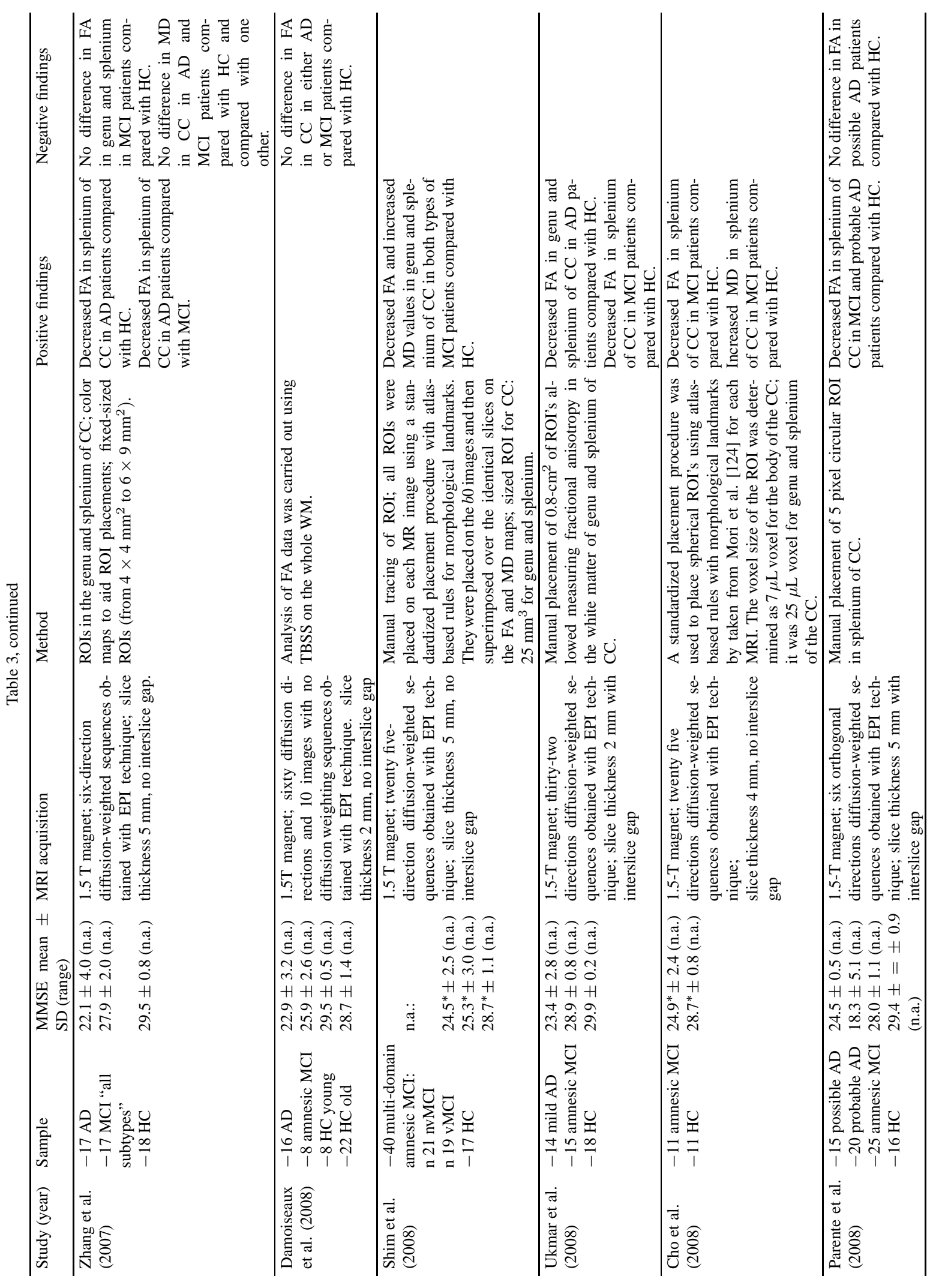




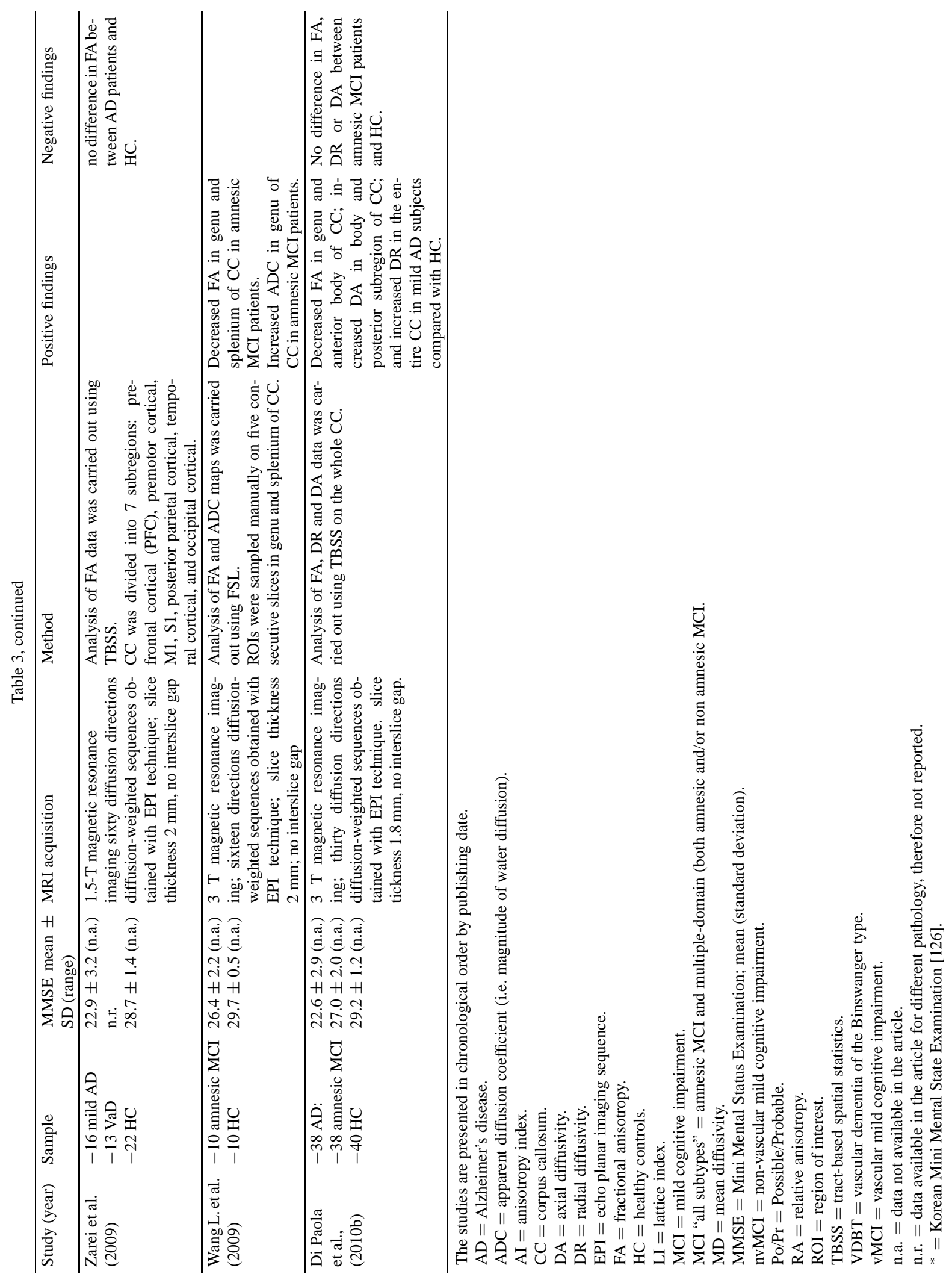


Table 4

Summary of ROI, VBM, DWI, and DTI studies of patients with Alzheimer's disease and mild cognitive impairment since 1997 showing corpus callosum changes

\begin{tabular}{|c|c|c|c|c|c|c|c|c|}
\hline \multirow{2}{*}{ Patients } & \multirow{2}{*}{ Techniques } & \multirow{2}{*}{ Studies } & \multirow{2}{*}{ Total CC Area } & \multirow{2}{*}{ Anterior CC } & \multicolumn{3}{|c|}{ Body } & \multirow{2}{*}{ Posterior CC } \\
\hline & & & & & A & $\mathrm{M}$ & $\mathrm{P}$ & \\
\hline \multirow[t]{35}{*}{ AD "all stages" } & ROI & Lyoo et al., (1997) & & + & + & + & + & + \\
\hline & & Hampel et al., (1998) & + & + & & & & + \\
\hline & & Teipel et al., (1998) & + & + & + & & & + \\
\hline & & Thompson et al., (1998) & & & & & & + \\
\hline & & Pantel et al., (1998) & + & + & + & & & \\
\hline & & Hanyu et al., (1999b) & + & & & & & + \\
\hline & & Teipel et al., (1999) & + & + & + & & & + \\
\hline & & Pantel et al., (1999) & + & + & + & + & & + \\
\hline & & Yamauchi et al., (2000) & + & & & & & + \\
\hline & & Black et al., (2000) & + & + & + & & + & + \\
\hline & & Teipel et al., (2002) & + & + & & & & + \\
\hline & & Teipel et al., (2003) & + & + & & & & + \\
\hline & & Hensel et al., (2004) & & & & & & \\
\hline & & Thomann et al., (2006) & + & + & + & + & & \\
\hline & & Tomaiuolo et al., (2007) & + & + & + & & & + \\
\hline & & Li et al., (2008) & & + & + & + & & + \\
\hline & & Hallem et al., (2008) & + & + & & & & + \\
\hline & VBM & Good et al., (2002) & + & & & & & \\
\hline & & Thomann et al., (2006) & & + & + & & & \\
\hline & & Chaim et al., (2007) & & + & + & & + & + \\
\hline & & Li et al., (2008) & & & & & & + \\
\hline & DWI & Sandson et al., (1999) & & & & & & \\
\hline & & Hanyu et al., (1999a) & & + & & & & + \\
\hline & & Hanyu et al., (1999b) & & + & & & & + \\
\hline & & Bozzao et al., (2001) & & & & & & \\
\hline & DTI & Rose et al., (2000) & & & & & & + \\
\hline & & Bozzali et al., (2002) & & + & & & & + \\
\hline & & Takahashi et al., (2002) & & & & & & + \\
\hline & & Head et al., (2004) & & & & & & \\
\hline & & Fellgiebel et al., (2004) & & & & & & \\
\hline & & Sugihara et al., (2004) & & & & & & \\
\hline & & Duan et al., (2006) & & & & & & + \\
\hline & & Stahl et al., (2007) & & & & & & \\
\hline & & Teipel et al., (2007) & & + & & & & \\
\hline & & Zhang et al., (2007) & & & & & & + \\
\hline \multirow[t]{3}{*}{ Severe AD } & ROI & Di Paola et al., (2010a) & & + & + & & & + \\
\hline & VBM & Di Paola et al., (2010a) & & + & + & & & + \\
\hline & DTI & Parente et al., (2008) & & & & & & + \\
\hline Moderate AD & ROI & Ortiz Alonso (2000) & & & + & + & & + \\
\hline \multirow[t]{18}{*}{ Mild AD } & ROI & Lyoo et al., (1997) & & & & & + & + \\
\hline & & Hensel et al., (2002) & + & & & & & \\
\hline & & Teipel et al., (2003) & & & & & & + \\
\hline & & Hensel et al., (2005) & & & & & & \\
\hline & & Wang PJ et al., (2006) & + & & & & & + \\
\hline & & Zarei et al., (2009) & & & & & & \\
\hline & & Di Paola et al., (2010a) & & & & & & \\
\hline & VBM & Di Paola et al., (2010a) & & & & & & \\
\hline & & Di Paola et al., (2010b) & & + & & & & + \\
\hline & DWI & Bozzao et al., (2001) & & & & & & \\
\hline & DTI & Choi et al., (2005) & & & & & & \\
\hline & & Medina et al., (2006) & & & & & & \\
\hline & & Naggara et al., (2006) & & & & & & + \\
\hline & & Xie et al., (2006) & & + & + & & & \\
\hline & & Damoiseaux et al., (2008) & & & & & & \\
\hline & & Ulkmar et al., (2008) & & & & & & + \\
\hline & & Parente et al., (2008) & & & & & & \\
\hline & & Zarei et al., (2009) & & & & & & \\
\hline
\end{tabular}


Table 4, continued

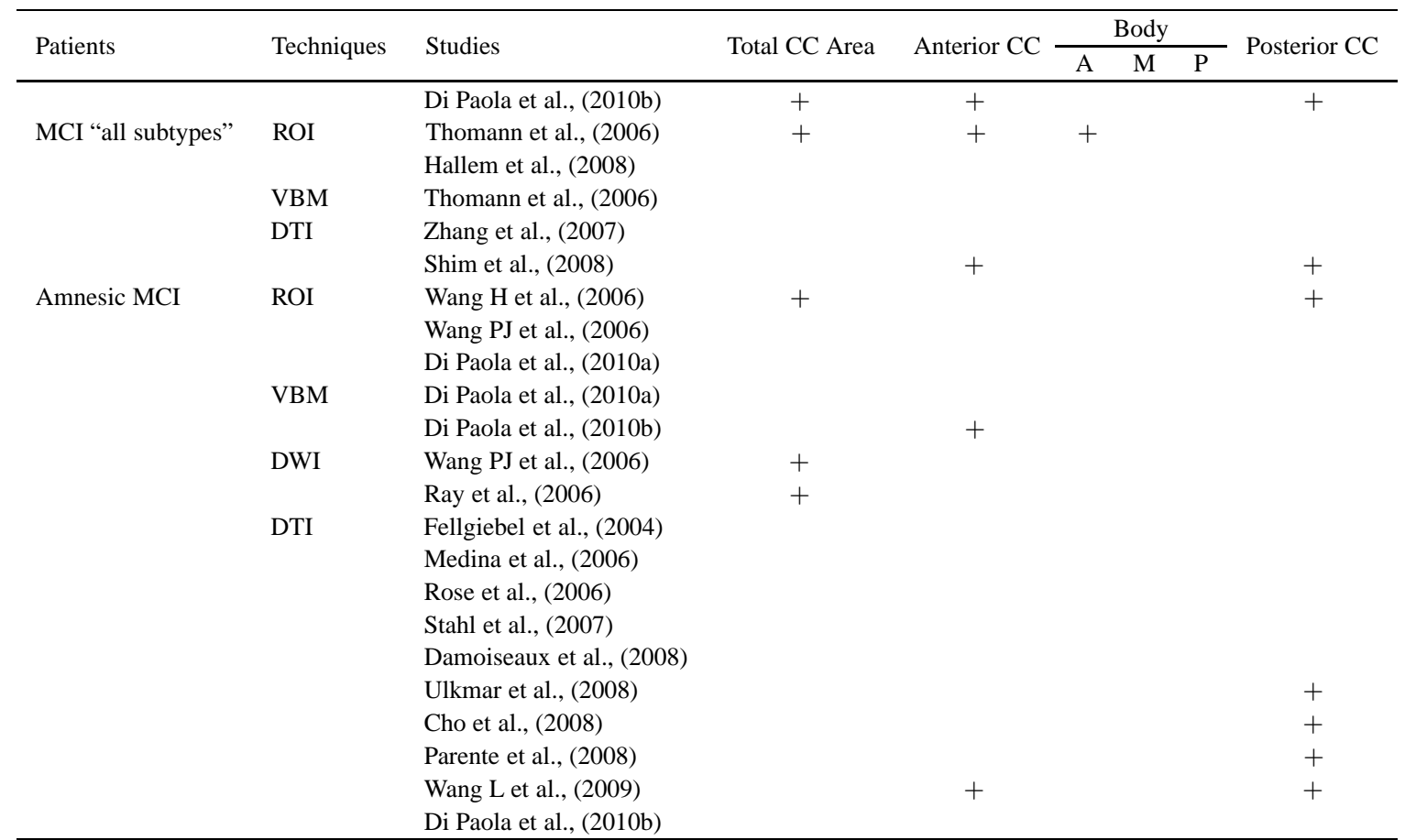

$\mathrm{AD}=$ Alzheimer's disease.

$\mathrm{CC}=$ corpus callosum.

$\mathrm{MA}=$ mild ambiguous (similar to $\mathrm{MCI}$ ).

$\mathrm{MCI}=$ mild cognitive impairment

Anterior $\mathrm{CC}=$ rostrum and genu.

Body ( $\mathrm{A}=$ anterior; $\mathrm{M}=$ mid; $\mathrm{P}=$ posterior body).

Posterior $\mathrm{CC}=$ isthmus and splenium.

brain regions could account for general deficits in executive functions and attention in AD.

Finally, the body of the $\mathrm{CC}$ is most involved in motor and somato-sensory functions, which are usually spared in $\mathrm{AD}$ patients.

\section{Possible underlying mechanisms}

The basic assumption is that callosal atrophy in $\mathrm{AD}$ is the anatomical correlate of Wallerian degeneration of commissural nerve fibers. Therefore, it might show the same pattern of neocortical neurodegeneration. Based on the Wallerian degeneration hypothesis and on the AD neuronal degeneration pattern [103,104], the posterior CC subregions should be involved in the earlier stages of the disease and the anterior CC subregions only in the later stages. Nevertheless, several studies [20, $21,82,89$ ] found that a reduction in the genu of the CC was already present in the early and preclinical stages of $\mathrm{AD}$.

It has been recently suggested that myelin breakdown is an important component of the illness process in $\mathrm{AD}[72,105,106]$. According to this hypothesis, latemylenating fibers should be more susceptible to myelin breakdown. The susceptibility of this subset of axons to myelin breakdown [107-110] may constitute an alternative mechanism through which the progression of cortical AD pathology occurs in the direction opposite to myelination [93], that is, the fibers that myelinate first in development are the last to be affected by AD and those that myelinate much later in normal development are the first to be affected by the AD degenerative process $[72,106]$.

The CC contains late-myelinating fibers in the genu $[98,99]$ and early-myelinating fibers in the splenium. Thus, it seems plausible to affirm that both Wallerian degeneration and myelin breakdown mechanisms are responsible for the region-specific illness effects. In this view, Wallerian degeneration affects the posterior CC subregion that receives axons directly from those brain areas (temporo-parietal lobe regions) that are primarily affected by AD pathology. Differently, the myelin breakdown process might affect the later- 
myelinating CC subregion, causing changes in the genu of the CC already in the early stage of the disease.

We tested the hypothesis that both Wallerian degeneration and myelin breakdown might be responsible for the region-specific callosal change detected in the mild AD patients in our a VBM and DTI study [21]. We followed the assumption, arising out of experiments on animal models, that a reduction in DR might signify a loss of myelin integrity and that a reduction of DA might implicate axonal damage expected with Wallerian degeneration [71,73,74]. Our results [21] suggest that both these mechanisms affecting the callosal WM are present. Indeed, we found atrophy in posterior and anterior subregions of the $\mathrm{CC}$ already in the early stage of $\mathrm{AD}$ (mild AD) and in amnesic MCI (see VBM data). However, the atrophy seemed to be due to different factors (see DTI data). In the anterior CC, we found loss of the preference of water diffusion in fiber direction (decreased FA) and major diffusion in the direction perpendicular to the CC fibers (increased DR). A change in DR not mirrored by a similar change in DA (such as that observed in the anterior portion of the CC) would most probably be caused by specific damage to the myelin sheaths that restrict DR. Thus, these changes suggest a loss of myelin integrity, possibly due to a myelin breakdown mechanism. In the posterior CC subregion, we found an increase in water diffusion in the direction of the fibers (increased DA, no difference in FA). These changes suggest widespread tissue damage leading to a generalized increase in extracellular space due, for example, to the axonal atrophy expected with Wallerian degeneration.

\section{Discrepancies with previous findings}

The controversial results concerning regional atrophy of the CC are most likely due to the methods adopted across studies, such as the different criteria used to select patients, the different stages of illness considered, and the different number of participants. Regarding the criteria used to select patients, here we report only a few examples. Thomann and collaborators [10] defined MCI patients according to the Aging-associated Cognitive Decline (AACD) criteria [111], which have been demonstrated to capture a larger group of patients than the MCI criteria. They also included people with cognitive impairment of a non-amnesic nature [112] and assigned the diagnosis of MCI with higher probability [113]. Therefore, this MCI group [10] was clearly more heterogeneous than groups in other studies. Yamauchi et al. [14] studied AD with early onset, which is considered a peculiar type of AD. In fact, it has been shown that AD patients with early onset have a typical and different topographical pattern of brain atrophy than patients with late onset $\mathrm{AD}$, with possible consequences on $\mathrm{CC}$ subregion changes during the course of AD [114,115].

Furthermore, the different degree of AD severity in some previous samples may also have been responsible for discrepant results. Many studies included AD patients with different degrees of pathology, for example, from mild to severe $[7,14,15]$ or from mild to moderate $[8,10,42]$ (see Tables 1, 2, 3). Thus, results may have been biased by the presence of subjects at different illness stages.

We have to consider that the vast majority of studies are cross-sectional, comparing AD patients and controls. Thus, anatomical changes described in AD patients could have existed prior to the onset of the illness and considered as a risk factor in AD. To solve this issue, in the near future follow-up investigations are strongly required in order to clarify how $\mathrm{CC}$ changes longitudinally in preclinical and clinical AD.

\section{Limitations of the techniques}

In early studies, the CC was manually traced (ROI studies) and segmented according to common parcellation schemes, that is, according to Witelson [44], or Hampel [18] (see Table 1 and Fig. 2). These callosal segmentation methods have generated controversy with respect to the assumed topography of the callosal fibers [48]. In a previous study [7], we demonstrated that the pre-definition of callosal regions can give rise to erroneous results. To overcome these limits, some studies investigated callosal morphology using ROI analysis, which does not involve traditional parcellation $[20,43,46]$, or applying an automated technique, such as VBM $[8,10,20,66]$, which completely eliminates the manual tracing step.

Nevertheless, the VBM technique also has limitations. One limitation is related to the variety of options available for implementing the VBM [49,116]. Senjem et al. [49] found that 1) changes in the image processing chain of the VBM noticeably influenced the results of inter-group morphometric comparisons; and 2) optimized VBM, using custom template and prior images, improved the plausibility of inter-group comparisons, presumably due to improved segmentation and spatial normalization. Thus, optimized VBM produces different results from those obtained with standard VBM. Prior to Senjem et al. [49], other authors had already 
pointed out the importance of spatial normalization, emphasizing that imperfect spatial normalization may affect the validity of VBM results [64,117,118].

There may be several reasons for the discrepant findings in DWI and DTI studies. First, the anisotropy indices from DWI are estimated from ADCs in three orthogonal directions, resulting in rotationally variant measurements that might differ if patients' heads have different sizes and are not oriented in the same way [119]. Thus, results are influenced by the different head positions of the subjects. DTI studies represent a step forward in this direction, because the scalar quantities associated with diffusion tensor (D) are invariant with respect to rotation of the coordinate system and, therefore, independent of the laboratory reference frame in which D is measured (i.e., they have the same value irrespective of the relative orientation of the "laboratory" and "fiber" frames of reference) [120]. Another aspect that can in part explain the variability in the results of DWI and DTI studies is how accurate the studies are in determining the location of changes. The latter can be inferred basically from ROI analyses $[40,41,89]$, voxel-wise comparisons [32,82,84], or projecting diffusion values onto a tract-based template (TBSS) [85]. These approaches, however, all make assumptions about the correspondence of tract locations across subjects [121].

Moreover, with respect to the ROI analyses (the ones most frequently adopted in the DTI studies we reviewed; see Table 3 ), variability of results can be accounted for by the size and the placement of the ROIs across studies. As the placement of the ROIs is operator-dependent, care must be taken to place the ROIs only in WM areas to avoid partial volume effects through CSF spaces. This is because intravoxel fiber incoherence diminishes the measured FA value. Thus, large ROIs are more likely to include other tissue than just WM, diminishing the FA value. Furthermore, the number of ROIs simultaneously examined in the studies and the difference in sample size (fixed vs variable) can influence results.

Furthermore, the VBM-style approach in DTI studies presents problems related to image registration and smoothing [122]. The first aspect can be generally expressed as the confidence we have that any given standard space voxel contains data from the same part of the same WM tract in each subject. A second problem with VBM-style analyses is the standard practice of spatially smoothing data before computing voxelwise statistics. In fact, the amount of smoothing can greatly affect the final results, but there is no princi- pled way of deciding how much smoothing is the "correct" amount [123]. Smoothing also increases effective partial volume effect, a problem with VBM-style approaches particularly when applied to data such as FA. The use of TBSS $[21,85,87]$ seems to overcome the limitations due to alignment of FA images from multiple subjects and to the arbitrariness of choosing the degree of spatial smoothing. TBSS solves these issues by means of carefully tuned nonlinear registration followed by projection onto an alignment-invariant tract representation (the "mean FA skeleton") with no spatial smoothing. This projection step removes the effect of cross-subject spatial variability that remains after the non-linear registration.

New possibilities in the research of WM callosal anatomy arise from the use of DTI in conjunction with fiber tractography. DTI-based tractography provides unique access to in vivo information about the topography of callosal fibers $[48,124]$. The technique allows reconstruction of the topographic arrangement of transcallosal fiber tracts projecting into specific cortical areas. Basically two ROIs are drawn, one is the entire $\mathrm{CC}$ and the other is each cortical area of projection. Then, a fiber tracking software is used to compute a 3D trajectory between the two ROIs. In both studies cited $[48,124]$, the streamline fiber tracking method was based on fiber assignment by continuous tracking (FACT) [125]. The track trajectories follow the principal eigenvectors (the principal orientation of the fiber tract within the WM). When the 3D fiber track trajectory enters a neighboring voxel, the fiber track's direction is altered to match the direction of the new voxel's primary eigenvector. The 3D fiber track is allowed to continue from voxel to voxel until it enters a region of FA less than 0.02 , turns an angle greater than $50^{\circ}$ between two consecutive voxels, or exits the brain.

Thus, DTI-based tractography is able to give information about the anatomical parcellation and cortical connectivity of CC subregions. This aspect is of great interest especially for those neurodegenerative disorders that affect the transcallosal connectivity.

However, DTI-based tractography has its own limits: it is prone to noise, partial volume effects, crossing fibers and to image resolution. Thus, future works would substantially benefit from DTI-based tractography especially if the limits of the technique will be improved with a better spatial resolution of DTI acquisitions, a greater number of diffusion-encoding gradients, and a more adequate representation of orientational distributions. 


\section{Conclusions}

Overall, the data suggest that studying the $\mathrm{CC}$ contributes to understanding the mechanisms underlying the progression of WM changes in AD and to expanding knowledge of its role in cerebral cognitive functioning. For this purpose, the application of different MRI techniques (e.g., traditional structural MRI and DTI) is crucial, because the measurement of multimodal parameters can offer a clearer picture of the WM in $\mathrm{AD}$.

\section{ACKNOWLEDGMENTS}

We wish to thank Dr Roberta Querini for her precious help in finding the articles and Mr. Gregory Lynn Oxidine for his help in editing the manuscript. This work was in part supported by the Italian Ministry of Health (RF.06-07-08 and RC 06-07-08-09/A).

Authors' disclosures available online (http://www.jalz.com/disclosures/view.php?id=214).

\section{REFERENCES}

[1] Hua X, Leow AD, Parikshak N, Lee S, Chiang MC, Toga AW, Jack CR, Jr., Weiner MW, Thompson PM (2008) Tensor-based morphometry as a neuroimaging biomarker for Alzheimer's disease: an MRI study of $676 \mathrm{AD}, \mathrm{MCI}$, and normal subjects. Neuroimage 43, 458-469.

[2] Hua X, Leow AD, Lee S, Klunder AD, Toga AW, Lepore N, Chou YY, Brun C, Chiang MC, Barysheva M, Jack CR, Jr., Bernstein MA, Britson PJ, Ward CP, Whitwell JL, Borowski B, Fleisher AS, Fox NC, Boyes RG, Barnes J, Harvey D, Kornak J, Schuff N, Boreta L, Alexander GE, Weiner MW, Thompson PM, Alzheimer's Disease Neuroimaging I (2008) $3 \mathrm{D}$ characterization of brain atrophy in Alzheimer's disease and mild cognitive impairment using tensor-based morphometry. Neuroimage 41, 19-34.

[3] Bronge L, Bogdanovic N, Wahlund LO (2002) Postmortem MRI and histopathology of white matter changes in Alzheimer brains. A quantitative, comparative study. Dement Geriatr Cogn Disord 13, 205-212.

[4] Smith CD, Snowdon DA, Wang H, Markesbery WR (2000) White matter volumes and periventricular white matter hyperintensities in aging and dementia. Neurology 54, 838-842.

[5] Scheltens P, Barkhof F, Leys D, Wolters EC, Ravid R, Kamphorst W (1995) Histopathologic correlates of white matter changes on MRI in Alzheimer's disease and normal aging. Neurology 45, 883-888.

[6] Brun A, Englund E (1986) A white matter disorder in dementia of the Alzheimer type: a pathoanatomical study. Ann Neurol 19, 253-262.

[7] Tomaiuolo F, Scapin M, Di Paola M, Le Nezet P, Fadda L, Musicco M, Caltagirone C, Collins DL (2007) Gross anatomy of the corpus callosum in Alzheimer's disease: regions of degeneration and their neuropsychological correlates. Dement Geriatr Cogn Disord 23, 96-103.
[8] Chaim TM, Duran FL, Uchida RR, Perico CA, de Castro CC, Busatto GF (2007) Volumetric reduction of the corpus callosum in Alzheimer's disease in vivo as assessed with voxel-based morphometry. Psychiatry Res 154, 59-68.

[9] Wang PJ, Saykin AJ, Flashman LA, Wishart HA, Rabin LA, Santulli RB, McHugh TL, MacDonald JW, Mamourian AC (2006) Regionally specific atrophy of the corpus callosum in AD, MCI and cognitive complaints. Neurobiol Aging 27, 1613-1617.

[10] Thomann PA, Wustenberg T, Pantel J, Essig M, Schroder J (2006) Structural changes of the corpus callosum in mild cognitive impairment and Alzheimer's disease. Dement Geriatr Cogn Disord 21, 215-220.

[11] Teipel SJ, Bayer W, Alexander GE, Bokde AL, Zebuhr Y, Teichberg D, Muller-Spahn F, Schapiro MB, Moller HJ, Rapoport SI, Hampel H (2003) Regional pattern of hippocampus and corpus callosum atrophy in Alzheimer's disease in relation to dementia severity: evidence for early neocortical degeneration. Neurobiol Aging 24, 85-94.

[12] Teipel SJ, Bayer W, Alexander GE, Zebuhr Y, Teichberg D, Kulic L, Schapiro MB, Moller HJ, Rapoport SI, Hampel H (2002) Progression of corpus callosum atrophy in Alzheimer disease. Arch Neurol 59, 243-248.

[13] Hampel H, Teipel SJ, Alexander GE, Pogarell O, Rapoport SI, Moller HJ (2002) In vivo imaging of region and cell type specific neocortical neurodegeneration in Alzheimer's disease. Perspectives of MRI derived corpus callosum measurement for mapping disease progression and effects of therapy. Evidence from studies with MRI, EEG and PET. $J$ Neural Transm 109, 837-855.

[14] Yamauchi H, Fukuyama H, Nagahama Y, Katsumi Y, Hayashi T, Oyanagi C, Konishi J, Shio H (2000) Comparison of the pattern of atrophy of the corpus callosum in frontotemporal dementia, progressive supranuclear palsy, and Alzheimer's disease. J Neurol Neurosurg Psychiatry 69, 623-629.

[15] Teipel SJ, Hampel H, Pietrini P, Alexander GE, Horwitz B, Daley E, Moller HJ, Schapiro MB, Rapoport SI (1999) Region-specific corpus callosum atrophy correlates with the regional pattern of cortical glucose metabolism in Alzheimer disease. Arch Neurol 56, 467-473.

[16] Thompson PM, Moussai J, Zohoori S, Goldkorn A, Khan AA, Mega MS, Small GW, Cummings JL, Toga AW (1998) Cortical variability and asymmetry in normal aging and Alzheimer's disease. Cereb Cortex 8, 492-509.

[17] Teipel SJ, Hampel H, Alexander GE, Schapiro MB, Horwitz B, Teichberg D, Daley E, Hippius H, Moller HJ, Rapoport SI (1998) Dissociation between corpus callosum atrophy and white matter pathology in Alzheimer's disease. Neurology 51, 1381-1385

[18] Hampel H, Teipel SJ, Alexander GE, Horwitz B, Teichberg D, Schapiro MB, Rapoport SI (1998) Corpus callosum atrophy is a possible indicator of region- and cell type-specific neuronal degeneration in Alzheimer disease: a magnetic resonance imaging analysis. Arch Neurol 55, 193-198.

[19] Lyoo IK, Satlin A, Lee CK, Renshaw PF (1997) Regional atrophy of the corpus callosum in subjects with Alzheimer's disease and multi-infarct dementia. Psychiatry Res 74, 63-72.

[20] Di Paola M, Luders E, Di Iulio F, Varsi AE, Sancesario G, Passafiume D, Thompson PM, Caltagirone C, Toga AW, Spalletta G (2010) Callosal atrophy in mild cognitive impairment and Alzheimer's disease: Different effects in different stages. Neuroimage 49, 141-149.

[21] Di Paola M, Di Iulio F, Cherubini A, Blundo C, Casini AR, Sancesario G, Passafiume D, Caltagirone C, Spalletta G 
(2010b) When, where and how corpus callosal changes in preclinical and clinical AD using multimodal MRI at 3 Tesla. Neurology, in press.

[22] Tomimoto H, Lin JX, Matsuo A, Ihara M, Ohtani R, Shibata M, Miki Y, Shibasaki H (2004) Different mechanisms of corpus callosum atrophy in Alzheimer's disease and vascular dementia. J Neurol 251, 398-406.

[23] Fellgiebel A, Wille P, Muller MJ, Winterer G, Scheurich A, Vucurevic G, Schmidt LG, Stoeter P (2004) Ultrastructural hippocampal and white matter alterations in mild cognitive impairment: a diffusion tensor imaging study. Dement Geriatr Cogn Disord 18, 101-108.

[24] Pantel J, Schroder J, Essig M, Minakaran R, Schad LR, Friedlinger M, Jauss M, Knopp MV (1998) Corpus callosum in Alzheimer's disease and vascular dementia - a quantitative magnetic resonance study. J Neural Transm Suppl 54, 129-136.

[25] Pantel J, Schroder J, Jauss M, Essig M, Minakaran R, Schonknecht P, Schneider G, Schad LR, Knopp MV (1999) Topography of callosal atrophy reflects distribution of regional cerebral volume reduction in Alzheimer's disease. Psychiatry Res 90, 181-192.

[26] Leys D, Pruvo JP, Parent M, Vermersch P, Soetaert G, Steinling M, Delacourte A, Defossez A, Rapoport A, Clarisse J, Petit H (1991) Could Wallerian degeneration contribute to leuko-araiosis in subjects free of any vascular disorder? $J$ Neurol Neurosurg Psychiatry 54, 46-50.

[27] Kaufer DI, Miller BL, Itti L, Fairbanks LA, Li J, Fishman J, Kushi J, Cummings JL (1997) Midline cerebral morphometry distinguishes frontotemporal dementia and Alzheimer's disease. Neurology 48, 978-985.

[28] Hanyu H, Asano T, Sakurai H, Imon Y, Iwamoto T, Takasaki M, Shindo H, Abe K (1999) Diffusion-weighted and magnetization transfer imaging of the corpus callosum in Alzheimer's disease. J Neurol Sci 167, 37-44.

[29] Hanyu H, Imon Y, Sakurai H, Iwamoto T, Takasaki M, Shindo H, Kakizaki D, Abe K (1999) Regional differences in diffusion abnormality in cerebral white matter lesions in patients with vascular dementia of the Binswanger type and Alzheimer's disease. Eur J Neurol 6, 195-203.

[30] Sandson TA, Felician O, Edelman RR, Warach $\mathrm{S}$ (1999) Diffusion-weighted magnetic resonance imaging in Alzheimer's disease. Dement Geriatr Cogn Disord 10, 166171.

[31] Black SE, Moffat SD, Yu DC, Parker J, Stanchev P, Bronskill M (2000) Callosal atrophy correlates with temporal lobe volume and mental status in Alzheimer's disease. Can J Neurol Sci 27, 204-209.

[32] Rose SE, Chen F, Chalk JB, Zelaya FO, Strugnell WE, Benson M, Semple J, Doddrell DM (2000) Loss of connectivity in Alzheimer's disease: an evaluation of white matter tract integrity with colour coded MR diffusion tensor imaging. $J$ Neurol Neurosurg Psychiatry 69, 528-530.

[33] Bozzao A, Floris R, Baviera ME, Apruzzese A, Simonetti G (2001) Diffusion and perfusion MR imaging in cases of Alzheimer's disease: correlations with cortical atrophy and lesion load. AJNR Am J Neuroradiol 22, 1030-1036.

[34] Good CD, Johnsrude IS, Ashburner J, Henson RN, Friston KJ, Frackowiak RS (2001) A voxel-based morphometric study of ageing in 465 normal adult human brains. Neuroimage 14, 21-36.

[35] Bozzali M, Falini A, Franceschi M, Cercignani M, Zuffi M, Scotti G, Comi G, Filippi M (2002) White matter damage in Alzheimer's disease assessed in vivo using diffusion tensor magnetic resonance imaging. J Neurol Neurosurg Psychiatry 72, 742-746.

[36] Takahashi S, Yonezawa H, Takahashi J, Kudo M, Inoue T, Tohgi H (2002) Selective reduction of diffusion anisotropy in white matter of Alzheimer disease brains measured by 3.0 Tesla magnetic resonance imaging. Neurosci Lett 332, 45-48.

[37] Head D, Buckner RL, Shimony JS, Williams LE, Akbudak E, Conturo TE, McAvoy M, Morris JC, Snyder AZ (2004) Differential vulnerability of anterior white matter in nondemented aging with minimal acceleration in dementia of the Alzheimer type: evidence from diffusion tensor imaging. Cereb Cortex 14, 410-423.

[38] Wiltshire K, Foster S, Kaye JA, Small BJ, Camicioli R (2005) Corpus callosum in neurodegenerative diseases: findings in Parkinson's disease. Dement Geriatr Cogn Disord 20, 345351.

[39] Teipel SJ, Stahl R, Dietrich O, Schoenberg SO, Perneczky R, Bokde AL, Reiser MF, Moller HJ, Hampel H (2007) Multivariate network analysis of fiber tract integrity in Alzheimer's disease. Neuroimage 34, 985-995.

[40] Stahl R, Dietrich O, Teipel SJ, Hampel H, Reiser MF, Schoenberg SO (2007) White matter damage in Alzheimer disease and mild cognitive impairment: assessment with diffusiontensor MR imaging and parallel imaging techniques. Radiology 243, 483-492.

[41] Zhang Y, Schuff N, Jahng GH, Bayne W, Mori S, Schad L, Mueller S, Du AT, Kramer JH, Yaffe K, Chui H, Jagust WJ, Miller BL, Weiner MW (2007) Diffusion tensor imaging of cingulum fibers in mild cognitive impairment and Alzheimer disease. Neurology 68, 13-19.

[42] Li S, Pu F, Shi F, Xie S, Wang Y, Jiang T (2008) Regional white matter decreases in Alzheimer's disease using optimized voxel-based morphometry. Acta Radiol 49, 84-90.

[43] Hallam BJ, Brown WS, Ross C, Buckwalter JG, Bigler ED, Tschanz JT, Norton MC, Welsh-Bohmer KA, Breitner JC (2008) Regional atrophy of the corpus callosum in dementia. J Int Neuropsychol Soc 14, 414-423.

[44] Witelson SF (1989) Hand and sex differences in the isthmus and genu of the human corpus callosum. A postmortem morphological study. Brain 112(Pt 3), 799-835.

[45] Hensel A, Wolf H, Kruggel F, Riedel-Heller SG, Nikolaus C, Arendt T, Gertz HJ (2002) Morphometry of the corpus callosum in patients with questionable and mild dementia. $J$ Neurol Neurosurg Psychiatry 73, 59-61.

[46] Wang H, Su MY (2006) Regional pattern of increased water diffusivity in hippocampus and corpus callosum in mild cognitive impairment. Dement Geriatr Cogn Disord 22, 223229.

[47] Weis S, Jellinger K, Wenger E (1991) Morphometry of the corpus callosum in normal aging and Alzheimer's disease. $J$ Neural Transm Suppl 33, 35-38.

[48] Hofer S, Frahm J (2006) Topography of the human corpus callosum revisited - comprehensive fiber tractography using diffusion tensor magnetic resonance imaging. Neuroimage 32, 989-994.

[49] Senjem ML, Gunter JL, Shiung MM, Petersen RC, Jack CR, Jr. (2005) Comparison of different methodological implementations of voxel-based morphometry in neurodegenerative disease. Neuroimage 26, 600-608.

[50] Petersen RC, Smith GE, Waring SC, Ivnik RJ, Tangalos EG, Kokmen E (1999) Mild cognitive impairment: clinical characterization and outcome. Arch Neurol 56, 303-308.

[51] Petersen RC (2004) Mild cognitive impairment as a diagnostic entity. J Intern Med 256, 183-194. 
[52] Lopez OL, Kuller LH, Becker JT, Dulberg C, Sweet RA, Gach HM, Dekosky ST (2007) Incidence of dementia in mild cognitive impairment in the cardiovascular health study cognition study. Arch Neurol 64, 416-420.

[53] Sydykova D, Stahl R, Dietrich O, Ewers M, Reiser MF, Schoenberg SO, Moller HJ, Hampel H, Teipel SJ (2007) Fiber connections between the cerebral cortex and the corpus callosum in Alzheimer's disease: a diffusion tensor imaging and voxel-based morphometry study. Cereb Cortex 17, 2276-2282.

[54] Jancke L, Staiger JF, Schlaug G, Huang Y, Steinmetz H (1997) The relationship between corpus callosum size and forebrain volume. Cereb Cortex 7, 48-56.

[55] Jancke L, Preis S, Steinmetz H (1999) The relation between forebrain volume and midsagittal size of the corpus callosum in children. Neuroreport 10, 2981-2985.

[56] Wang PP, Doherty S, Hesselink JR, Bellugi U (1992) Callosal morphology concurs with neurobehavioral and neuropathological findings in two neurodevelopmental disorders. Arch Neurol 49, 407-411.

[57] Schmitt JE, Eliez S, Warsofsky IS, Bellugi U, Reiss AL (2001) Corpus callosum morphology of Williams syndrome: relation to genetics and behavior. Dev Med Child Neurol $\mathbf{4 3}$, 155-159.

[58] Hensel A, Wolf H, Busse A, Arendt T, Gertz HJ (2005) Association between global brain volume and the rate of cognitive change in elderly humans without dementia. Dement Geriatr Cogn Disord 19, 213-221.

[59] Ortiz Alonso T, Martinez Castillo E, Fernandez Lucas A, Arrazola Garcia J, Maestu Unturbe F, Lopez-Ibor JJ (2000) Callosal atrophy and associated electromyographic responses in Alzheimer's disease and aging. Electromyogr Clin Neurophysiol 40, 465-475.

[60] Luders E, Narr KL, Zaidel E, Thompson PM, Jancke L, Toga AW (2006) Parasagittal asymmetries of the corpus callosum. Cereb Cortex 16, 346-354.

[61] Thompson PM, MacDonald D, Mega MS, Holmes CJ, Evans AC, Toga AW (1997) Detection and mapping of abnormal brain structure with a probabilistic atlas of cortical surfaces. J Comput Assist Tomogr 21, 567-581.

[62] Thompson PM, Schwartz C, Toga AW (1996) Highresolution random mesh algorithms for creating a probabilistic 3D surface atlas of the human brain. Neuroimage 3, 19-34.

[63] Thompson PM, Schwartz C, Lin RT, Khan AA, Toga AW (1996) Three-dimensional statistical analysis of sulcal variability in the human brain. $J$ Neurosci 16, 4261-4274.

[64] Ashburner J, Friston KJ (2000) Voxel-based morphometry the methods. Neuroimage 11, 805-821.

[65] Ashburner J, Friston KJ (2005) Unified segmentation. Neuroimage 26, 839-851.

[66] Good CD, Scahill RI, Fox NC, Ashburner J, Friston KJ, Chan D, Crum WR, Rossor MN, Frackowiak RS (2002) Automatic differentiation of anatomical patterns in the human brain: validation with studies of degenerative dementias. Neuroimage 17, 29-46.

[67] Basser PJ, Jones DK (2002) Diffusion-tensor MRI: theory, experimental design and data analysis - a technical review. NMR Biomed 15, 456-467.

[68] Neil J, Miller J, Mukherjee P, Huppi PS (2002) Diffusion tensor imaging of normal and injured developing human brain a technical review. NMR Biomed 15, 543-552.

[69] Beaulieu C (2002) The basis of anisotropic water diffusion in the nervous system - a technical review. NMR Biomed 15, $435-455$.
[70] Assaf BA, Mohamed FB, Abou-Khaled KJ, Williams JM, Yazeji MS, Haselgrove J, Faro SH (2003) Diffusion tensor imaging of the hippocampal formation in temporal lobe epilepsy. AJNR Am J Neuroradiol 24, 1857-1862.

[71] Sun SW, Song SK, Harms MP, Lin SJ, Holtzman DM, Merchant KM, Kotyk JJ (2005) Detection of age-dependent brain injury in a mouse model of brain amyloidosis associated with Alzheimer's disease using magnetic resonance diffusion tensor imaging. Exp Neurol 191, 77-85.

[72] Bartzokis G (2004) Age-related myelin breakdown: a developmental model of cognitive decline and Alzheimer's disease. Neurobiol Aging 25, 5-18; author reply 49-62.

[73] Song SK, Sun SW, Ju WK, Lin SJ, Cross AH, Neufeld AH (2003) Diffusion tensor imaging detects and differentiates axon and myelin degeneration in mouse optic nerve after retinal ischemia. Neuroimage 20, 1714-1722.

[74] Song SK, Sun SW, Ramsbottom MJ, Chang C, Russell J, Cross AH (2002) Dysmyelination revealed through MRI as increased radial (but unchanged axial) diffusion of water. Neuroimage 17, 1429-1436.

[75] Choi SJ, Lim KO, Monteiro I, Reisberg B (2005) Diffusion tensor imaging of frontal white matter microstructure in early Alzheimer's disease: a preliminary study. J Geriatr Psychiatry Neurol 18, 12-19.

[76] Muller MJ, Greverus D, Dellani PR, Weibrich C, Wille PR, Scheurich A, Stoeter P, Fellgiebel A (2005) Functional implications of hippocampal volume and diffusivity in mild cognitive impairment. Neuroimage 28, 1033-1042.

[77] Sundgren PC, Dong Q, Gomez-Hassan D, Mukherji SK, Maly P, Welsh R (2004) Diffusion tensor imaging of the brain: review of clinical applications. Neuroradiology 46, 339-350.

[78] Ray KM, Wang H, Chu Y, Chen YF, Bert A, Hasso AN, Su MY (2006) Mild cognitive impairment: apparent diffusion coefficient in regional gray matter and white matter structures. Radiology 241, 197-205.

[79] Naggara O, Oppenheim C, Rieu D, Raoux N, Rodrigo S, Dalla Barba G, Meder JF (2006) Diffusion tensor imaging in early Alzheimer's disease. Psychiatry Res 146, 243-249.

[80] Duan JH, Wang HQ, Xu J, Lin X, Chen SQ, Kang Z, Yao ZB (2006) White matter damage of patients with Alzheimer's disease correlated with the decreased cognitive function. Surg Radiol Anat 28, 150-156.

[81] Pierpaoli C, Basser PJ (1996) Toward a quantitative assessment of diffusion anisotropy. Magn Reson Med 36, 893-906.

[82] Xie S, Xiao JX, Gong GL, Zang YF, Wang YH, Wu HK, Jiang XX (2006) Voxel-based detection of white matter abnormalities in mild Alzheimer disease. Neurology 66, 18451849.

[83] Ukmar M, Makuc E, Onor ML, Garbin G, Trevisiol M, Cova MA (2008) Evaluation of white matter damage in patients with Alzheimer's disease and in patients with mild cognitive impairment by using diffusion tensor imaging. Radiol Med 113, 915-922.

[84] Medina D, DeToledo-Morrell L, Urresta F, Gabrieli JD, Moseley M, Fleischman D, Bennett DA, Leurgans S, Turner DA, Stebbins GT (2006) White matter changes in mild cognitive impairment and AD: A diffusion tensor imaging study. Neurobiol Aging 27, 663-672.

[85] Damoiseaux JS, Smith SM, Witter MP, Arigita EJ, Barkhof F, Scheltens P, Stam CJ, Zarei M, Rombouts SA (2009) White matter tract integrity in aging and Alzheimer's disease. Hum Brain Mapp 30, 1051-1059.

[86] Parente DB, Gasparetto EL, da Cruz LC, Jr., Domingues RC, 
Baptista AC, Carvalho AC, Domingues RC (2008) Potential role of diffusion tensor MRI in the differential diagnosis of mild cognitive impairment and Alzheimer's disease. AJR Am J Roentgenol 190, 1369-1374.

[87] Zarei M, Johansen-Berg H, Smith S, Ciccarelli O, Thompson AJ, Matthews PM (2006) Functional anatomy of interhemispheric cortical connections in the human brain. J Anat 209, 311-320.

[88] Rose SE, McMahon KL, Janke AL, O'Dowd B, de Zubicaray G, Strudwick MW, Chalk JB (2006) Diffusion indices on magnetic resonance imaging and neuropsychological performance in amnestic mild cognitive impairment. J Neurol Neurosurg Psychiatry 77, 1122-1128.

[89] Shim YS, Yoon B, Shon YM, Ahn KJ, Yang DW (2008) Difference of the hippocampal and white matter microalterations in MCI patients according to the severity of subcortical vascular changes: neuropsychological correlates of diffusion tensor imaging. Clin Neurol Neurosurg 110, 552-561.

[90] Cho H, Yang DW, Shon YM, Kim BS, Kim YI, Choi YB, Lee KS, Shim YS, Yoon B, Kim W, Ahn KJ (2008) Abnormal integrity of corticocortical tracts in mild cognitive impairment: a diffusion tensor imaging study. $J$ Korean Med Sci 23, 477-483.

[91] Wang L, Goldstein FC, Veledar E, Levey AI, Lah JJ, Meltzer CC, Holder CA, Mao H (2009) Alterations in cortical thickness and white matter integrity in mild cognitive impairment measured by whole-brain cortical thickness mapping and diffusion tensor imaging. AJNR Am J Neuroradiol 30, 893-899.

[92] Zarei M, Damoiseaux JS, Morgese C, Beckmann CF, Smith SM, Matthews PM, Scheltens P, Rombouts SA, Barkhof F (2009) Regional white matter integrity differentiates between vascular dementia and Alzheimer disease. Stroke 40, 773779.

[93] Braak H, Braak E (1997) Frequency of stages of Alzheimerrelated lesions in different age categories. Neurobiol Aging 18, 351-357.

[94] Schmahmann JD PD (2006) Fiber pathways of the brain, Oxford Universiy Press, New York.

[95] Thompson PM, Hayashi KM, de Zubicaray G, Janke AL, Rose SE, Semple J, Herman D, Hong MS, Dittmer SS, Doddrell DM, Toga AW (2003) Dynamics of gray matter loss in Alzheimer's disease. J Neurosci 23, 994-1005.

[96] Braak H, Braak E (1991) Neuropathological stageing of Alzheimer-related changes. Acta Neuropathol 82, 239-259.

[97] Galton CJ, Patterson K, Xuereb JH, Hodges JR (2000) Atypical and typical presentations of Alzheimer's disease: a clinical, neuropsychological, neuroimaging and pathological study of 13 cases. Brain 123(Pt 3), 484-498.

[98] Aboitiz F, Rodriguez E, Olivares R, Zaidel E (1996) Agerelated changes in fibre composition of the human corpus callosum: sex differences. Neuroreport 7, 1761-1764.

[99] Aboitiz F, Scheibel AB, Fisher RS, Zaidel E (1992) Fiber composition of the human corpus callosum. Brain Res $\mathbf{5 9 8}$, 143-153.

[100] Petrides M (2005) Lateral prefrontal cortex: architectonic and functional organization. Philos Trans R Soc Lond B Biol Sci 360, 781-795.

[101] Petrides M (2002) The mid-ventrolateral prefrontal cortex and active mnemonic retrieval. Neurobiol Learn Mem 78, 528-538.

[102] Petrides M (1996) Specialized systems for the processing of mnemonic information within the primate frontal cortex. Philos Trans R Soc Lond B Biol Sci 351, 1455-1461; discussion 1461-1452.
[103] Brun A, Englund E (2002) Regional pattern of degeneration in Alzheimer's disease: neuronal loss and histopathological grading. Histopathology 41, 40-55.

[104] Brun A, Englund E (1981) Regional pattern of degeneration in Alzheimer's disease: neuronal loss and histopathological grading. Histopathology 5, 549-564.

[105] Bartzokis G, Cummings JL, Sultzer D, Henderson VW, Nuechterlein KH, Mintz J (2003) White matter structural integrity in healthy aging adults and patients with Alzheimer disease: a magnetic resonance imaging study. Arch Neurol 60, 393-398.

[106] Bartzokis G, Sultzer D, Lu PH, Nuechterlein KH, Mintz J, Cummings JL (2004) Heterogeneous age-related breakdown of white matter structural integrity: implications for cortical disconnection in aging and Alzheimer's disease. Neurobiol Aging 25, 843-851.

[107] Nieuwenhuys R (1999) Structure and organization of fibre systems In The central nervous system of vertebrates., ed. S, ed., Berlin.

[108] Tang Y, Nyengaard JR, Pakkenberg B, Gundersen HJ (1997) Age-induced white matter changes in the human brain: a stereological investigation. Neurobiol Aging 18, 609-615.

[109] Hildebrand C, Remahl S, Persson H, Bjartmar C (1993) Myelinated nerve fibres in the CNS. Prog Neurobiol 40, 319384.

[110] Meier-Ruge W, Ulrich J, Bruhlmann M, Meier E (1992) Agerelated white matter atrophy in the human brain. Ann NY Acad Sci 673, 260-269.

[111] Levy R (1994) Aging-associated cognitive decline. Working Party of the International Psychogeriatric Association in collaboration with the World Health Organization. Int Psychogeriatr 6, 63-68.

[112] Richards M, Touchon J, Ledesert B, Richie K (1999) Cognitive decline in ageing: are AAMI and AACD distinct entities? Int J Geriatr Psychiatry 14, 534-540.

[113] Busse A, Bischkopf J, Riedel-Heller SG, Angermeyer MC (2003) Mild cognitive impairment: prevalence and incidence according to different diagnostic criteria. Results of the Leipzig Longitudinal Study of the Aged (LEILA75+). Br J Psychiatry 182, 449-454.

[114] Frisoni GB, Pievani M, Testa C, Sabattoli F, Bresciani L, Bonetti M, Beltramello A, Hayashi KM, Toga AW, Thompson PM (2007) The topography of grey matter involvement in early and late onset Alzheimer's disease. Brain 130, 720-730.

[115] Karas G, Scheltens P, Rombouts S, van Schijndel R, Klein M, Jones B, van der Flier W, Vrenken H, Barkhof F (2007) Precuneus atrophy in early-onset Alzheimer's disease: a morphometric structural MRI study. Neuroradiology 49, 967976.

[116] Keller SS, Wilke M, Wieshmann UC, Sluming VA, Roberts $\mathrm{N}$ (2004) Comparison of standard and optimized voxel-based morphometry for analysis of brain changes associated with temporal lobe epilepsy. Neuroimage 23, 860-868.

[117] Bookstein FL (2001) Voxel-based morphometry should not be used with imperfectly registered images. Neuroimage $\mathbf{1 4}$, 1454-1462.

[118] Salmond CH, Ashburner J, Vargha-Khadem F, Connelly A, Gadian DG, Friston KJ (2002) The precision of anatomical normalization in the medial temporal lobe using spatial basis functions. Neuroimage 17, 507-512.

[119] Kantarci K, Jack CR, Jr., Xu YC, Campeau NG, O'Brien PC, Smith GE, Ivnik RJ, Boeve BF, Kokmen E, Tangalos EG, Petersen RC (2001) Mild cognitive impairment and Alzheimer 
disease: regional diffusivity of water. Radiology 219, 101107.

[120] Basser PJ, Mattiello J, LeBihan D (1994) MR diffusion tensor spectroscopy and imaging. Biophys $J$ 66, 259-267.

[121] Johansen-Berg H, Behrens TE (2006) Just pretty pictures? What diffusion tractography can add in clinical neuroscience. Curr Opin Neurol 19, 379-385.

[122] Smith SM, Jenkinson M, Johansen-Berg H, Rueckert D, Nichols TE, Mackay CE, Watkins KE, Ciccarelli O, Cader MZ, Matthews PM, Behrens TE (2006) Tract-based spatial statistics: voxelwise analysis of multi-subject diffusion data. Neuroimage 31, 1487-1505.

[123] Jones DK, Symms MR, Cercignani M, Howard RJ (2005) The effect of filter size on VBM analyses of DT-MRI data. Neuroimage 26, 546-554.

[124] Huang H, Zhang J, Jiang H, Wakana S, Poetscher L, Miller MI, van Zijl PC, Hillis AE, Wytik R, Mori S (2005) DTI trac- tography based parcellation of white matter: application to the mid-sagittal morphology of corpus callosum. Neuroimage 26, 195-205.

[125] Mori S, Crain BJ, Chacko VP, van Zijl PC (1999) Threedimensional tracking of axonal projections in the brain by magnetic resonance imaging. Ann Neurol 45, 265-269.

[126] Kang YW, Na DL, Hahn SH (1997) A validity study on the Korean Mini-Mental State Examination (K-MMSE) in dementia patients. J Korean Neurol Assoc 15, 300-308.

[127] Duara R, Kushch A, Gross-Glenn K, Barker WW, Jallad B, Pascal S, Loewenstein DA, Sheldon J, Rabin M, Levin B, Lubs H (1991) Neuroanatomic differences between dyslexic and normal readers on magnetic resonance imaging scans. Arch Neurol 48, 410-416.

[128] Larsen JP, Höien T, Ödegaard H (1992) Magnetic resonance imaging of the corpus callosum in developmental dysiexia. Cogn Neuropsychol 9, 123-134. 